\title{
Increased Neuromuscular Activity Reduces Sprouting in Partially Denervated Muscles
}

\author{
Siu Lin Tam, Vey Archibald, Balvinder Jassar, Neil Tyreman, and Tessa Gordon \\ Department of Pharmacology, Division of Neuroscience, University of Alberta, Edmonton, Canada T6G 2S2
}

The effects of increasing neural activity on sprouting remain unclear and controversial. In a rat model of partial denervation of skeletal muscles, we investigated the effect of neuromuscular activity on sprouting. Rat hindlimb muscles were partially denervated by avulsion of either L4 or L5 spinal root. Immediately after partial denervation, the rats were divided into three groups: (1) normal caged activity, (2) running exercise on wheels, $8 \mathrm{hr}$ daily, and (3) functional electrical stimulation (FES) of sciatic nerves, $20 \mathrm{~Hz}$ for $8 \mathrm{hr}$ daily. At 1 month, muscle unit (MU) enlargement was quantitated electrophysiologically and histochemically. MU twitch force was increased by four- to fivefold by partial denervation in extensively denervated tibialis anterior (TA) and medial gastrocnemius (MG) and by approximately twofold in moderately denervated plantaris $(P L)$ and soleus (SOL). For the extensively denervated TA and MG mus- cles, MU enlargement, measured electrophysiologically, declined significantly after an average of $1757 \pm 310 \mathrm{~m} / \mathrm{d}$ running exercise and daily FES for 1 month. The detrimental effects on MU enlargement were much less but significant in the moderately denervated PL and did not reach statistical significance in the moderately denervated SOL muscle. Histochemical evaluation of sprouting showed a reduction in the number of sprouts in the extensively denervated TA muscle, but not the moderately denervated PL and SOL muscles, by increased neuromuscular activity. Thus, increased neuromuscular activity is detrimental primarily in muscles that are extensively denervated, and the MUs are smaller than under conditions in which the muscles experience normal physiological levels of activation.

Key words: sprouting; motor unit; motoneuron disease; neuromuscular activity; partial denervation; poliomyelitis
Poliomyelitis, the early stages of amyotrophic lateral sclerosis (ALS), spinal cord trauma, and motoneuron destruction associated with cancer are only some of the neuromuscular conditions resulting in compensatory axonal sprouting and, in turn, MU enlargement (Brown et al., 1981; Halstead and Wiechers, 1987). MU enlargement is unfortunately restricted to a limit of five- to eightfold such that sprouting compensates for up to $85 \%$ loss of muscle units (MUs) (Thompson and Jansen, 1977; Brown and Ironton, 1978; Yang et al., 1990; Rafuse et al., 1992). Thus when $<20 \%$ of intact MUs remain and sprouting cannot reinnervate all denervated muscle fibers, muscle weakness becomes evident (Luff et al., 1988; Rafuse et al., 1992; Rafuse and Gordon, 1996a,b).

The strong association of exercise with muscle strength and endurance has led naturally to attempts to optimize muscle function with exercise. However, the effects of neuromuscular activity on sprouting are both unclear and controversial because of the conflicting findings of previous studies of these effects. Some studies have shown that activity can promote sprouting or reinnervation (Ribchester, 1988; Einsiedel and Luff, 1994) or that it has no effect at all (Gardiner and Faltus, 1986; Michel and Gardiner, 1989; Seburn and Gardiner, 1996), whereas others have shown inhibitory effects of activity on sprouting (Brown and

\footnotetext{
Received April 26, 2000; revised Oct. 13, 2000; accepted Oct. 23, 2000.

This work was supported by the Muscular Dystrophy Association of Canada. We thank the Alberta Heritage Foundation of Medical Research for supporting T.G. as a research scientist, and the Rick Hansen Man in Motion Legacy Fund and Alberta Heritage Foundation Medical Research for supporting S.L.T. as a research fellow. This work partially fulfilled the requirements for S.L.T.'s M.Sc. thesis.

Correspondence should be addressed to Dr. Tessa Gordon, Division of Neuroscience, 525 Heritage Medical Research Center, Faculty of Medicine, University of Alberta, Edmonton, Alberta T6G 2S2, Canada. E-mail: tessa.gordon@ualberta.ca. Copyright (C) 2001 Society for Neuroscience $0270-6474 / 01 / 210654-14 \$ 15.00 / 0$
}

Holland, 1979; Gardiner et al., 1984; Rafuse et al., 1992). In most of these studies, the extent of partial denervation was moderate, possibly contributing to the variability in the effects of increased neuromuscular activity on MU enlargement.

We have reexamined the issue in extensively denervated muscles using two functionally different muscles, tibialis anterior, flexor (TA) and medial gastrocnemius, extensor (MG) muscles, and compared the effectiveness of neuromuscular activity in modulating MU enlargement in these muscles with the more frequently studied soleus (SOL) and plantaris (PL) muscles. A further modification in the experimental approach has been to (1) document the extent of partial denervation for each muscle, (2) use complementary force measurement and histochemical method to quantitate MU enlargement and sprouting, respectively, and (3) compare the effect of natural (running on exercise wheels) and artificial [functional electrical stimulation (FES)] means of increasing neuromuscular activity on sprouting. We show that increased neuromuscular activity during the acute phase of sprouting is not beneficial for sprouting. In fact, increased neuromuscular activity is detrimental primarily in partially denervated muscles in which MUs enlarge by a factor of 2 or more, and the MUs are smaller than under conditions in which the muscles experience normal physiological levels of activation.

The present results have been presented previously in abstract form (Tam et al., 1995, 1996, 1997).

\section{MATERIALS AND METHODS}

Surgical procedures

A total of 55 female Sprague Dawley rats (body weight 180-200 gm) were used for these studies. Rats were fed normal rat food and supplied with water. Surgery was performed under surgical anesthesia (sodium pentobarbital administered intraperitoneally as $0.07 \mathrm{ml} / \mathrm{g}$ body weight) and aseptic conditions. A small incision near the L4 and L5 spinal roots was 
made on the back of the rats. Either the L4 $(n=23)$ or L5 $(n=20)$ spinal root was avulsed unilaterally to extensively ( $>80 \%$ partial denervation) denervate TA (L4 avulsion) or MG muscles (L5 avulsion) and moderately ( $\sim 50 \%$ partial denervation) denervate PL and SOL muscles. Immediately after partial denervation, the rats were divided into three groups. (1) Normal caged activity $(n=20)$ : rats were put back into their normal rat cages and allowed to continue their normal caged activity. (2) Natural running exercise on wheels $(n=11)$ : rats were allowed to run voluntarily on exercise wheels for $8 \mathrm{hr} / \mathrm{d}$. Throughout the $8 \mathrm{hr}$, running distance was recorded for individual rats. The running distance per day (i.e., $8 \mathrm{hr}$ ) for individual rats was calculated by dividing the total running distance by the total number of days. The average running distance per day was calculated by averaging the running distances per day of all rats. (3) FES $(n=12)$ : A $2 \mathrm{~cm}$ length of insulation was removed at the end of the two stainless steel wires to implant on either side of the sciatic nerve in the experimental leg for chronic electrical stimulation. In some cases, the insulated wires were externalized and attached to an external stimulator (Grass SD9) via an implanted connector, which was placed and secured on a pedestal at the back of the animal's head. The externalized wires were protected by a spring core on the outside such that the animal could not chew on them, and they were long enough ( $\sim 3$ feet long) to allow the animals to move freely. In others, the insulated wires remained internalized and attached to an implantable and locally made electrical stimulator that was turned on and off by a flash of light. Supramaximal pulses of $100 \mu \mathrm{sec}$ were delivered at $20 \mathrm{~Hz}$ for $8 \mathrm{hr} / \mathrm{d}$. Threshold voltage was established to evoke muscle twitch contractions. The voltage was set at $2 \times$ threshold.

The number of MUs recruited during exercise varies according to the muscle such that daily voluntary exercise does not necessarily recruit all MUs. We therefore used supramaximal electrical stimulation of sciatic nerve to recruit all MUs. We chose a low-stimulation frequency of $20 \mathrm{~Hz}$, the classical firing frequency of slow MUs in SOL muscle, which at continuous stimulation rates does not occlude muscle blood supply in either fast or slow muscles (Pette and Vrbova, 1992). We used $8 \mathrm{hr}$ of electrical stimulation in this study to ensure a high daily period of activity. Initially, stimulated muscles became fatigued rapidly (Pette and Vrbova, 1992; Gordon, 1995), but when associated with stimulation of angiogenesis and conversion of anaerobic to aerobic metabolism, the muscles became fatigue resistant, which was associated with conversion of muscle fiber type. The unoperated muscles of the left side hindlimb of the experimental rats served as contralateral controls.

One month later, implanted wires were removed from the animals of the FES group and checked visually to ensure that there was no corrosion, which could cause potential tissue damage. Muscle force and MU enlargement were evaluated in all four muscles using muscle and MU force measurements. Subsequently, TA and MG muscles were removed for staining for acid or alkaline-myosin ATPase, whereas PL and SOL muscles were removed for either toluidine blue histological staining or combined silver/acetylcholinesterase $(\mathrm{Ag} / \mathrm{AChE})$ histochemical staining.

Both electrophysiological and histochemical evaluations were performed in the PL and SOL muscles, where L4 or L5 avulsion resulted in moderate denervation with few exceptions of partial denervation that exceeded $75 \%$. Only electrophysiological evaluation was performed in the TA and MG muscles because they were prepared for cross-sectional histochemical analysis (myosin ATPase) and muscle fiber cross-sectional area (CSA) measurement to correct the force measurements for changes in CSA. To obtain morphological evidence of sprouting to complement the electrophysiological data in extensively denervated muscles, a further set of experiments was performed in a group of rats $(n=12)$. Avulsion of L4 spinal root was performed to extensively denervate the hindlimb flexor muscles $(n=8)$. Equal numbers of rats were subjected to either normal cage activity $(n=4)$ or natural running exercise on wheels $(n=$ $4,8 \mathrm{hr}$ daily). Unoperated rats $(n=4)$ were used as normal controls. At 4 weeks, rats were perfused transcardially with $4 \%$ buffered formalin, and fixed TA muscles were removed and prepared for Ag/AChE histochemical staining.

\section{Muscle and $M U$ force recordings}

At the end of the 4-week experimental treatment, muscle force and MU enlargement were evaluated by muscle and MU isometric force measurements in the final experiment. Rats were again anesthetized using sodium pentobarbital. Hydration and blood volume were maintained by hourly intravenous injection of saline solution via external jugular cannulas. The trachea was cannulated for mechanical ventilation. TA, MG, PL, and SOL muscles were isolated bilaterally by denervating all other
A
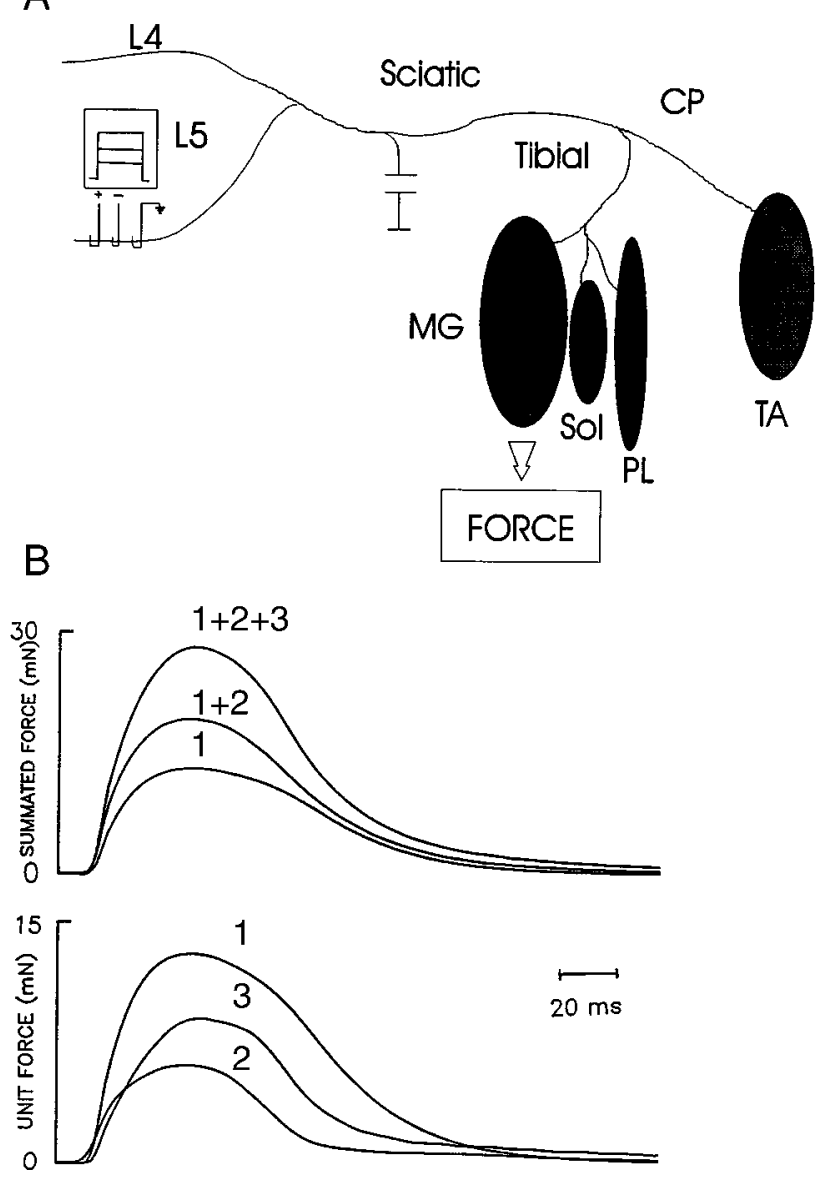

Figure 1. Muscle and MU twitch forces recordings. $A$, Each rat hindlimb muscle ( $T A$, tibialis anterior; $M G$, medial gastrocnemius; $P L$, plantaris; $S O L$, soleus) was isolated by denervating all other hindlimb muscles and attached to a force transducer. Ventral roots L4 and L5 were isolated. Whole-muscle twitch force elicited by stimulation of each ventral root (L4 or L5) was recorded. Ventral roots were then split into small filaments for stimulation of single motor axons. $B$, Single MU force was elicited by gradually increasing stimulation voltage to progressively recruit single MUs as judged by all-or-none increments in twitch force. Isometric twitch contractions (5-10) elicited at $1 \mathrm{~Hz}$ stimulation were digitized and averaged. Individual MU twitch force was obtained by digital subtraction.

hip, tail, and hindlimb muscles (Fig. $1 A$ ). Bipolar silver wires were placed on either side of the sciatic nerve for stimulation. Braided silk threads, 2.0 gauge, were tied to the distal muscle tendons for attachment to a force transducer, and the skin around the incision was closed loosely. A laminectomy from L3 to L6 spinal processes was performed to isolate the L4 and L5 spinal ventral roots bilaterally.

For each partially denervated and contralateral unoperated control muscle, isometric twitch and tetanic forces were recorded in response to suprathreshold $(2 \times$ threshold $)$ sciatic nerve stimulation. Maximal evoked muscle twitch and tetanic forces were measured in response to 1, 5, and 21 pulses at $100 \mathrm{~Hz}$ at a repetition rate of $0.5-1 \mathrm{~Hz}$. Recordings were made sequentially in the TA, MG, SOL, and PL muscles. The muscles and their innervation were separated sufficiently so that the evoked muscle contractions of the one muscle attached to the strain gauge was not interfered with by the contractions of the muscles that were not attached to the strain gauge. For each muscle, length for maximal twitch force was determined before the force recordings. Muscle tetanic force elicited by stimulation of each ventral root (L4 or L5) was recorded. Thereafter, MU force recordings were made sequentially in the same muscles. The sciatic nerve was stimulated to evoke whole-muscle contractions at regular intervals throughout the MU recording to check the integrity of the innervation. Recordings were discontinued if muscle contractions declined by $>10 \%$. The ventral roots were teased into small 
filaments, each of which contained approximately 5-10 motor axons to the muscle in which MU force recording was being performed. A single MU was isolated by the all-or-none recruitment of a twitch contraction (Fig. $1 B$ ) by increasing the stimulation voltage applied to the rootlet as shown in Figure $1 A$ and described previously (Tötösy de Zepetnek et al., 1992a). The signal was sufficiently amplified for visualization of the isometric twitch contraction on an oscilloscope screen and a Gould pen recorder with a $5 \mathrm{~V}$ maximum. The voltage of the $10 \mu \mathrm{sec}$ stimulus pulse applied to the rootlet was increased gradually until an all-or-none twitch contraction was evoked $50 \%$ of the time. The stimulus voltage was then increased to $2 \times$ threshold for signal averaging of 5-10 contractions repeated at $1 \mathrm{~Hz}$. The same method was repeated to recruit a second and up to seven MUs, using the same all-or-none criteria. The number of MUs recruited in this fashion was limited to approximately seven so that force increments were always clearly delineated.

As previously demonstrated for MU populations with twitch and tetanic forces that vary over a 10 -to 100 -fold range, at least $40 \%$ of the MU population must be sampled to adequately represent the population (Rafuse et al., 1992). Hence we recorded twitch forces in up to $40 \%$ of the MUs in the contralateral control muscles and all MUs in the partially denervated muscles. MUs were isolated first in the TA (L4 root avulsion) or MG (L5 root avulsion) muscle by splitting the remaining root containing an average of 10 MUs for the TA and MG muscles before isolating MUs in the PL and SOL muscles. The corresponding roots were teased on the contralateral side to record MUs in the corresponding intact muscles. In each experiment, MU recording from a single muscle was repeated after the nerves to the other three muscles were cut as a further check of the validity of the method.

\section{Histochemistry}

Acid or alkaline-myosin ATPase. After muscle and MU force recordings, TA and MG muscles were quickly removed, cut into three cross-sectional blocks, and frozen in isopentane cooled in liquid nitrogen. Cryostat cross sections (mainly from the middle portion of the muscles) at $12 \mu \mathrm{m}$ were cut and stained for acid or alkaline-myosin ATPase (Tötösy de Zepetnek et al., 1992b). Muscle fiber CSA was subsequently measured from these sections.

Combined Ag/AChE histochemical staining. PL and SOL muscles were removed and then fixed in $4 \%$ formalin overnight and cryoprotected by subsequent overnight incubation in gum sucrose solution. Muscles were then frozen in isopentane at $-74^{\circ} \mathrm{C}$. Cryostat longitudinal sections at 100 $\mu \mathrm{m}$ were cut and stained using combined $\mathrm{Ag} / \mathrm{AChE}$ histochemical staining to visualize the motor axons, sprouts, and endplates. For cholinesterase staining, $100 \mu \mathrm{m}$ cryostat longitudinal sections were collected in distilled water and incubated for $25 \mathrm{~min}$ at room temperature in a mixture of $0.01 \mathrm{M}$ Tris- $\mathrm{HCl}$ buffer, $\mathrm{pH} 7.2$, bromoindoxyl acetate, $1.65 \%$ potassium ferricyanide, $2.11 \%$ potassium ferrocyanide, and $1.11 \%$ calcium chloride. For silver staining, sections from acetylcholinesterase staining were (1) incubated in $20 \%$ silver nitrate for $15 \mathrm{~min}$, then (2) incubated in $3 \%$ sodium sulfite for $10 \mathrm{~min}$, and finally (3) developed in a mixture of silver nitrate and physical developer. Washing in distilled water was performed between steps. The number of sprouts and free endplates were subsequently counted from the sections. Silver staining revealed the motor axons as brown. AChE staining revealed the location of motor endplates by staining the enzyme, acetylcholinesterase, which locates at the synaptic lamina, greenish-blue. Unlike acetylcholine receptors, acetylcholinesterase stays indefinitely after denervation.

Toluidine blue. Because sufficient sprout counts were obtained from a representative number of PL and SOL muscles, the remaining muscles were prepared for toluidine blue histological staining and subsequently for measurement of muscle fiber CSA. Cryostat cross sections (from the middle portion of the muscles) at $12 \mu \mathrm{m}$ were cut and stained using 5\% toluidine blue solution. Muscle fiber CSA was then measured from these sections.

\section{Data analysis}

Muscle fiber CSA. We measured CSAs of sampled muscle fibers (at least $40 \%$ of the total number of muscle fibers) in both the partially denervated and contralateral TA, MG, PL, and SOL muscles using a microcomputer digitizing software program (JAVA, Jandel Scientific). Muscle fibers were sampled randomly throughout the muscle sections as described previously (Tötösy de Zepetnek et al., 1992b). In the partially denervated muscles, we found two distinct populations of size of muscle fibers: a smaller and a larger, which correspond to denervated and innervated muscle fibers, respectively. The mean CSA of the larger population, corresponding to the innervated muscle fibers in the partially denervated muscles, was used for correction of whole muscle twitch force of each muscle and MU twitch force of each single MU in each muscle. A systematic error associated with possible shrinkage $(\sim 10 \%)$ caused by tissue freezing did not affect the normalization of forces because it was done by multiplying the force by the ratio of CSA of the contralateral muscle to that of the experimental muscle. Because CSAs of both muscles were measured under the same conditions and criteria, any systematic errors were canceled out. The mean muscle fiber CSAs of both the partially denervated and contralateral TA, MG, PL, and SOL muscles for all experimental groups were calculated and are shown in Table 1.

$M U$ number and size, and whole muscle force. All MUs in each partially denervated muscle and at least $40 \%$ of MUs in contralateral control muscles were counted and sampled to obtain a representative mean MU twitch force in each case. The total number of MUs innervating each muscle was estimated by dividing the whole muscle twitch force by the mean MU twitch force of each muscle. This estimation of MU numbers was in agreement with the MU counts, there being no significant difference between them for any muscle. For the partially denervated TA muscles, for example, the estimated and recorded numbers of remaining MUs were, respectively, $7 \pm 2$ and $6 \pm 2$ after caged activity, $8 \pm 2$ and $7 \pm 1$ after running exercise, and $4 \pm 2$ and $5 \pm 2$ after FES for a total of 4-7 animals per group. MU twitch force of each single MU in each experimental muscle was corrected for changes in CSAs by multiplying the recorded force value by the ratio of the mean muscle fiber CSA of all contralateral muscles to that of all experimental muscles that belonged to the same experimental condition. The forces, which were corrected by CSAs, are referred to as "corrected" throughout this paper. MU force is the product of innervation ratio (IR; number of muscle fibers innervated by one motoneuron), muscle fiber CSA, and specific force (force per unit area of muscle fiber). Several studies have shown that MU force varies systematically with IR and CSA in both normal and reinnervated muscles (Kanda and Hashizume, 1992; Tötösy de Zepetnek et al., 1992a), but specific force does not change after reinnervation (Tötösy de Zepetnek et al., 1992a; Fu and Gordon, 1995a,b). Therefore, MU force corrected for muscle fiber CSA reasonably reflects IR.

Extent of partial denervation. Our previous study has shown that there is a bilateral symmetry of the left and right sides in the hindlimb muscle forces and innervation contributions of the ventral roots in normal rats (our unpublished data). The study showed that the mean difference between the two sides in the innervation contributions of L4 and L5 spinal roots caused by experimental and physiological variability was well within the acceptable limits. Similar findings have also been shown in studies using cats (Buller and Pope, 1977; Gordon et al., 1986). Therefore, we determined the contributions of L4 and L5 spinal roots to the muscles on the contralateral side to obtain a reasonable estimate of extent of partial denervation of the muscles on the experimental side. Muscle tetanic force elicited by the stimulation of each spinal root and sciatic nerve on the contralateral side were measured. The ratio of muscle tetanic force elicited by the stimulation of each spinal root to that elicited by the stimulation of sciatic nerve was determined and used to represent the extent of partial denervation of the muscles on the experimental side. To ensure the accuracy of the estimation, the number of remaining MUs on the experimental side was also counted electrophysiologically (see above).

Analysis of axonal sprouts and free endplates. Initially, we examined at least 3500 endplates in 18-22 longitudinal sections of two PL and two SOL muscles ( $>90 \%$ of all endplates). Subsequently, data from analysis of 500 endplates in the same muscles from a total of six sections from the middle portion of the muscle were not significantly different from data from the analysis of the 3500 endplates per muscle in the same two muscles. Hence, we analyzed 500 rather than the larger number of endplates subsequently for all the remaining muscles. Endplates from sections stained for combined $\mathrm{Ag} / \mathrm{AChE}$ histochemical staining were examined under light microscopy at a total magnification of $160 \times$ or $400 \times$ and classified as one of the following: (1) free endplates (endplates having no visible axonal attachment) and (2) endplates reinnervated by intranodal sprouts (axonal outgrowth coming out from a node of Ranvier), preterminal sprouts (axonal outgrowth originating from the myelin-free region of an axon at the entry point to the motor endplates), or ultraterminal sprouts (axonal outgrowth from the myelin-free axons within the motor endplate region). The percentage of endplates that were reinnervated by either type of sprouts was determined. The quantity of free endplates was determined by the percentage of free endplates 

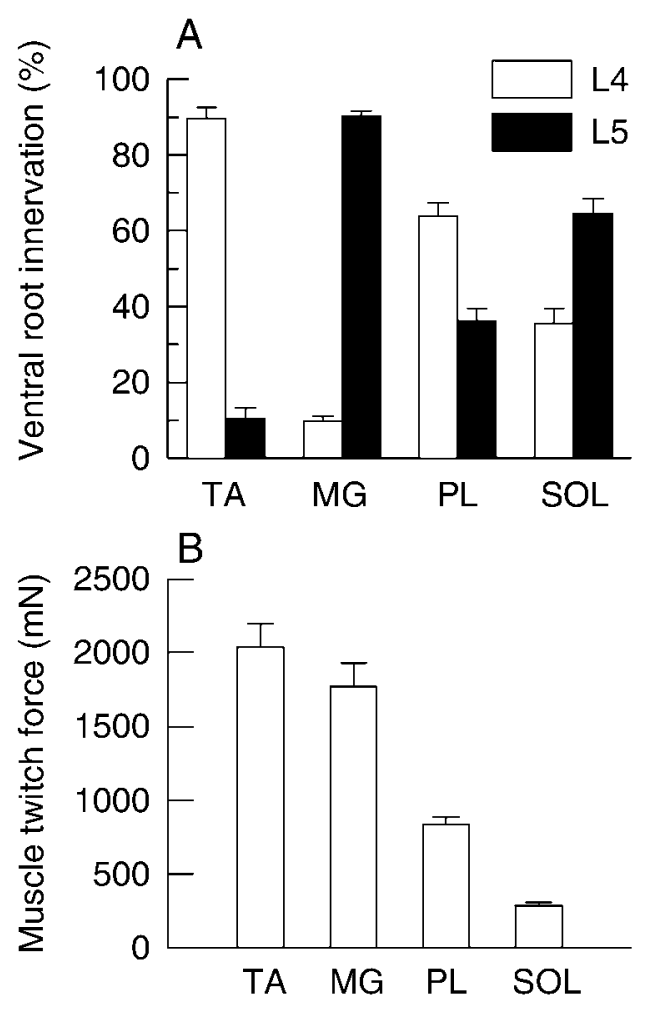
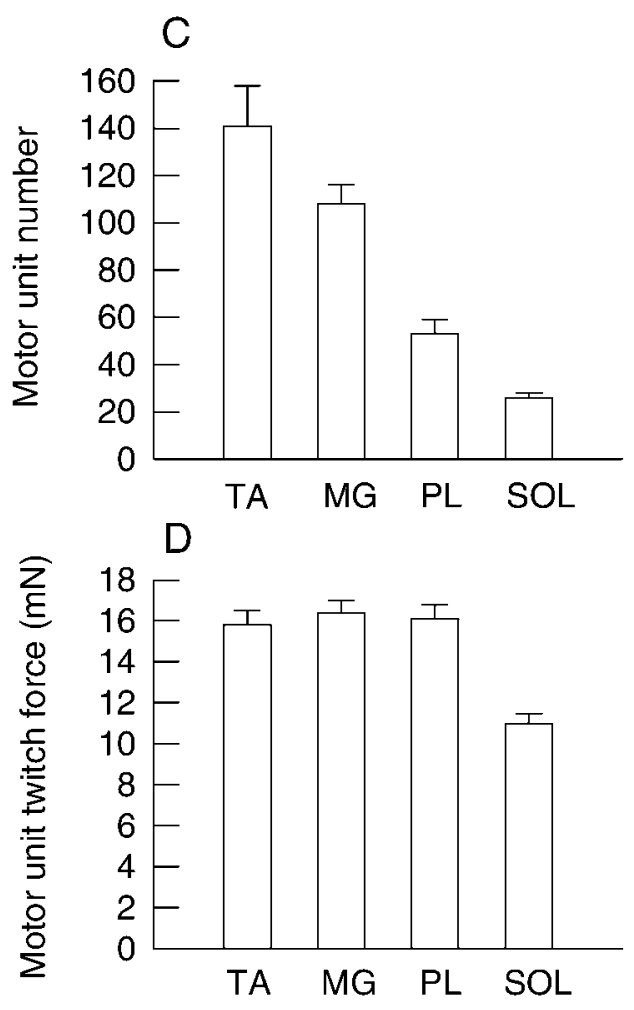

Figure 2. Mean $( \pm \mathrm{SE})$ percentage of ventral root L4 (open histograms) or L5 ( filled histograms) innervation $(A)$, mean muscle twitch forces $(B)$, mean MU numbers $(C)$, and mean $\mathrm{MU}$ twitch forces $(D)$ of TA, MG, PL, and SOL muscles. Avulsion of L4 spinal root resulted in $>80 \%$ denervation in TA muscle, ranging from 48 to $100 \%$ (average $89 \pm 3 \% ; n=21$ ). Avulsion of L5 spinal root resulted in $>80 \%$ denervation in $\mathrm{MG}$ muscle, ranging from 75 to $99 \%$ (average $90 \pm 2 \% ; n=20$ ), but avulsion of either L4 or L5 spinal roots resulted in less extensive denervation in PL muscle, ranging from 4 to $92 \%$ (average $45 \pm 4 \% ; n=39$ ), and SOL muscle, ranging from 2 to $95 \%$ (average $47 \pm 4 \% ; n=38$ ). TA, MG, PL, and SOL muscles had the mean MU numbers of $141 \pm 17(n=9), 108 \pm 8(n=$ 11), $53 \pm 6(n=10)$, and $26 \pm 2(n=$ $11)$, respectively; the mean muscle twitch forces of $2040 \pm 156(n=9)$, $1770 \pm 161(n=11), 836 \pm 52(n=10)$, and $28 \pm 24$ (11), respectively; and the mean MU twitch forces of $15.8 \pm 0.7$ $\left(n^{\prime}=245\right), 16.4 \pm 0.6\left(n^{\prime}=303\right), 1601 \pm$ $0.7\left(n^{\prime}=161\right)$, and $11.0 \pm 0.5\left(n^{\prime}=105\right)$, respectively. Muscle force varies more directly with mean number than mean MU force $(n=$ total number of muscles sampled for the calculation of the mean MU numbers; $n^{\prime}=$ total number of MUs sampled for the calculation of the mean MU twitch forces). from the total number of endplates sampled. All counting was "blind" in the sense that the investigator was not aware of the nature of the tissue samples being examined. The identity of muscles from the different experimental groups was unknown at the time of counting and encoded. The identity of muscles was revealed only after the counting was completed.

\section{Statistics}

Throughout this paper, means with SEs are given. Statistical significance of differences in the mean numbers of MUs, numbers of sprouts, and free endplates between control, partially denervated muscles with and without neural activation was determined using one-way ANOVA and subsequently Tukey's honestly significance difference (HSD) Test. One-way ANOVA was used to determine whether differences among the mean scores between and within experimental groups were statistically significant. When significant differences existed, Tukey's HSD test, one of the post hoc tests, was performed to determine the loci of the significance. The Kolmogorov-Smirnov test (Daniel, 1995) was applied to examine statistical significance of differences in cumulative distribution of MU twitch force between control, partially denervated muscles with and without neural activation. For all above statistical analyses, $p<0.05$ was regarded as significant.

\section{RESULTS}

Throughout this study, no significant difference was found in MU numbers and MU twitch forces between the contralateral control muscles for different experimental groups. Thus, the results from the contralateral control muscles for different experimental groups were grouped and used as an overall control. As for the quantitation of sprout and free-endplate numbers, there was no significant difference between the normal and the contralateral control muscles. Thus, the results from both groups were grouped and used as an overall control.

\section{MU numbers and reduction by partial denervation}

We reduced the number of intact MUs in TA, MG, PL, and SOL muscles by avulsion of either L4 or L5 spinal roots. The contribution of each spinal root to motor innervation of the muscles is bilaterally symmetrical (Buller and Pope, 1977). Hence, the extent of partial denervation of the experimental muscles was determined from the ratio of muscle tetanic force elicited by the stimulation of either L4 or L5 spinal root to that elicited by the stimulation of sciatic nerve on the contralateral unoperated control side. As shown in Figure $2 A$, stimulation of L4 ventral root evoked $>80 \%$ of the force in TA muscle and stimulation L5 ventral root evoked $>80 \%$ of the force in MG muscle, indicating that L4 ventral root carries the majority of motor axons to the TA muscle and L5 ventral root carries the majority of motor axons to the MG muscle. In comparison, PL and SOL muscles demonstrated a much less preferential distribution of motor axons in the L4 and L5 ventral roots. Also shown in Figure 2 are the differences in the muscles with respect to mean muscle twitch force (Fig. 2B), number of MUs (Fig. 2C), and MU twitch force (Fig. 2D). Muscle twitch force correlated more directly with MU number than mean MU twitch force, which was very similar in fast-twitch muscles and smaller in the slow-twitch SOL muscle, which contains predominantly slow MUs.

\section{MU enlargement by sprouting in extensively denervated muscles}

Avulsion of L4 spinal roots axotomized $>80 \%$ of the TA motoneurons, and avulsion of L5 spinal roots axotomized $>80 \%$ of the MG motoneurons. After partial denervation, 3-20 MUs remained ( $>80 \%$ partial denervation) in the TA and MG muscles 


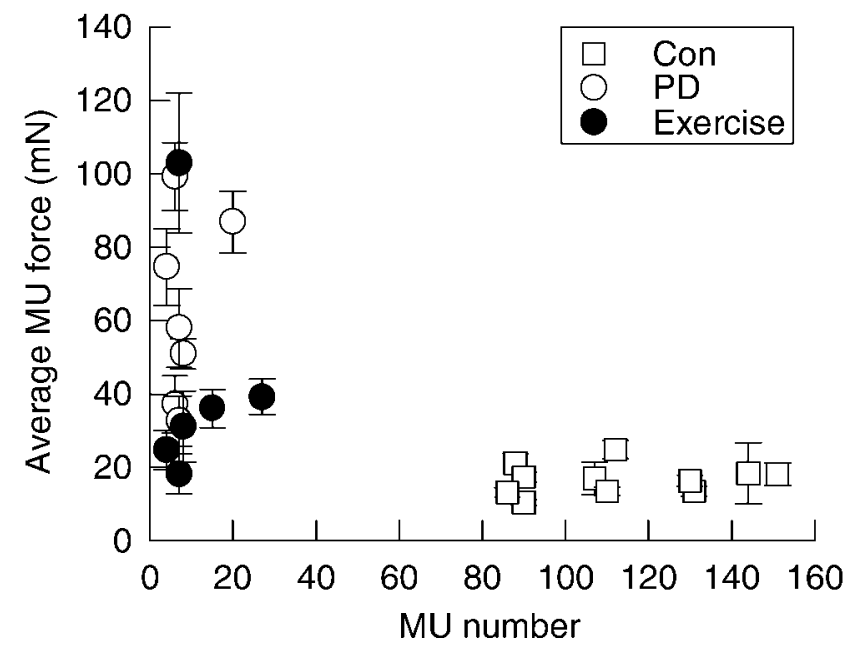

Figure 3. Average MU twitch force for MG muscle is plotted as a function of the MU number for partially denervated muscles that experienced caged activity $(\bigcirc)$ and running exercise $(\bullet)$, as compared with contralateral control muscles $(\square)$.

(MU $=7 \pm 2$ in both muscles) as compared with $133 \pm 14$ and $88 \pm 8$ MUs in contralateral control TA and MG muscles, respectively. In contrast to the insignificant difference between mean MU twitch forces in the contralateral control muscles, the mean twitch forces of the small number of remaining MUs varied widely between partially denervated muscles, as illustrated for the MG muscle in Figure 3. Although it is clear that the mean forces were generally significantly higher than forces in the contralateral control muscles, and that the average MU forces declined dramatically after exercise (Fig. 3), the mean values of MUs sampled from different rats varied widely from rat to rat. This variability is readily understood by the fact that section of $>80 \%$ of the motor axons in one ventral root leaves behind $<20 \%$ of the motor axons in the remaining intact ventral root. These remaining axons previously supplied MUs that developed forces randomly distributed within the 10-fold range of forces in the normally innervated muscle (Fig. 4). In view of this distribution, comparisons of mean force values after partial denervation do not adequately reflect the MU population. Collation of the few MU data from different rats in which muscles have been partially denervated provides a means of better representing the normal distribution whether the distribution is shown as the skewed distribution on arithmetic scales (Fig. $4 A$ ) or as semilogarithmic scales (Fig. 4B). Note how the collated distributions for the partially denervated muscles are similar to the normal distributions, as demonstrated previously for larger MU samples in cat muscles (Rafuse et al., 1992). The scatter and differences between the mean twitch forces of the few remaining MUs in the extensively partially denervated muscles demonstrate the wide variability between animals in the distribution of the MU forces in the L4 and L5 roots through which the motor axons exit the spinal cord (Fig. 3). Hence, the population of MUs in the partially denervated muscles is better represented by sampling many MUs from several animals for collation and direct comparison with the collated population of MU twitch forces from the control muscles, as shown in Figure 4. The distributions of MU forces in the contralateral control and partially denervated muscles were skewed to the left with more small force MUs than large (Fig. 4A). The distributions were normalized on semilogarithmic scales (Fig. 4B). Comparisons between
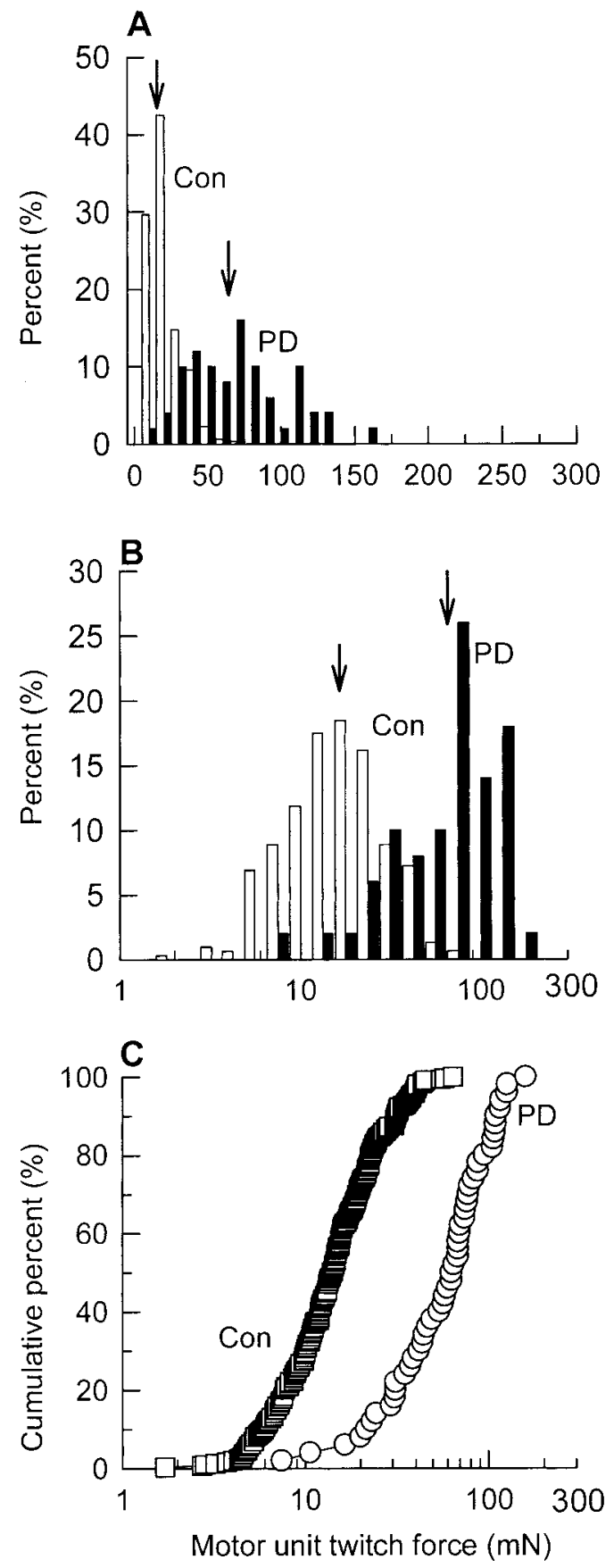

Figure 4. Percentage histograms of the distributions of MU twitch forces in partially denervated $\mathrm{MG}$ muscle $(P D)$ as compared with contralateral control (Con) MG muscle. The twitch force is plotted on a linear scale $(A)$ and a logarithmic scale $(B, C)$, and the distribution is designated as the percentage of total in $A$ and $B$ and as cumulative percentage in $C$. Note that the MU force distributions are skewed to the left on linear scales $(A)$ in contrast to a more normal distribution on semilogarithmic scales $(B)$. The enlarged twitch forces in the partially denervated muscles are shifted in parallel to the forces of the contralateral control muscles in the cumulative percentage histograms on semilogarithmic scales. This demonstrates that all MUs were enlarged to the same extent after partial denervation.

the distributions of normal and partially denervated muscles are very clearly represented by cumulative frequency histograms on semilogarithmic scales (Fig. 4C). A parallel shift in the distributions, after partial denervation, denotes the enlargement of all 
Table 1. Summary of mean \pm SE of muscle fiber CSA in TA, MG, PL, and SOL muscles in control, partially denervated muscles in rats experiencing normal caged activity (PD), partially denervated muscles after running exercise (PD + exercise), and partially denervated muscles with FES (PD + FES)

\begin{tabular}{|c|c|c|c|c|}
\hline \multirow{2}{*}{$\begin{array}{l}\text { Experimental } \\
\text { groups }\end{array}$} & \multicolumn{4}{|c|}{ Mean muscle fiber CSAs $\left(\mu \mathrm{m}^{2}\right)$} \\
\hline & TA & MG & PL & SOL \\
\hline Control & $3160 \pm 101$ & $3481 \pm 191$ & $1105 \pm 14$ & $1991 \pm 23$ \\
\hline $\mathrm{PD}+$ caged activity & $2396 \pm 292$ & $2851 \pm 651$ & $895 \pm 16$ & $1377 \pm 25$ \\
\hline $\mathrm{PD}+$ exercise & $1910 \pm 287$ & $3729 \pm 178$ & $1319 \pm 28$ & $1919 \pm 29$ \\
\hline $\mathrm{PD}+\mathrm{FES}$ & $1850 \pm 196$ & $2370 \pm 326$ & $1426 \pm 22$ & $1805 \pm 30$ \\
\hline
\end{tabular}

A total of 67 muscles (up to 11 muscles for each muscle type in each experimental group), including the contralateral control and partially denervated muscles, were sampled for muscle fiber CSA measurement.

Figure 5. Cumulative frequency histograms of distributions of MU twitch force after normalization for muscle fiber CSAs in partially denervated $T A(A), M G(B), P L$ $(C)$, and $S O L(D)$ muscles [partial denervation $(P D, O)]$ as compared with contralateral normally innervated muscles (Control, $\square$ ) from rats that experienced normal caged activity without either FES or running exercise on wheels. The cumulative distribution of MU twitch forces was plotted on a semilogarithmic scale with the result that logarithmic values of force are more normally distributed. In TA and MG muscles in which PD was $>80 \%$, MU twitch forces were significantly larger than control as shown by the significant rightward shift of the MU twitch force distributions $(p<$ 0.001). The shift in the MU twitch force distributions was much less but significant $(p<0.01)$ for moderately denervated $(\mathrm{PD}<80 \%) \mathrm{PL}$ and SOL muscles. For $T A$, $n^{\prime}=160($ Control $)$ and $n^{\prime}=45(P D)$; for $M G, n^{\prime}=199$ (Control) and $n^{\prime}=50(P D)$; for $P L, n^{\prime}=76$ (Control) and $n^{\prime}=204(P D)$; for SOL, $n^{\prime}=57$ (Control) and $n^{\prime}=169$ $(P D)(n=$ total number of muscles sampled for the calculation of the mean MU numbers; $n^{\prime}=$ total number of MUs sampled for MU twitch force measurement).

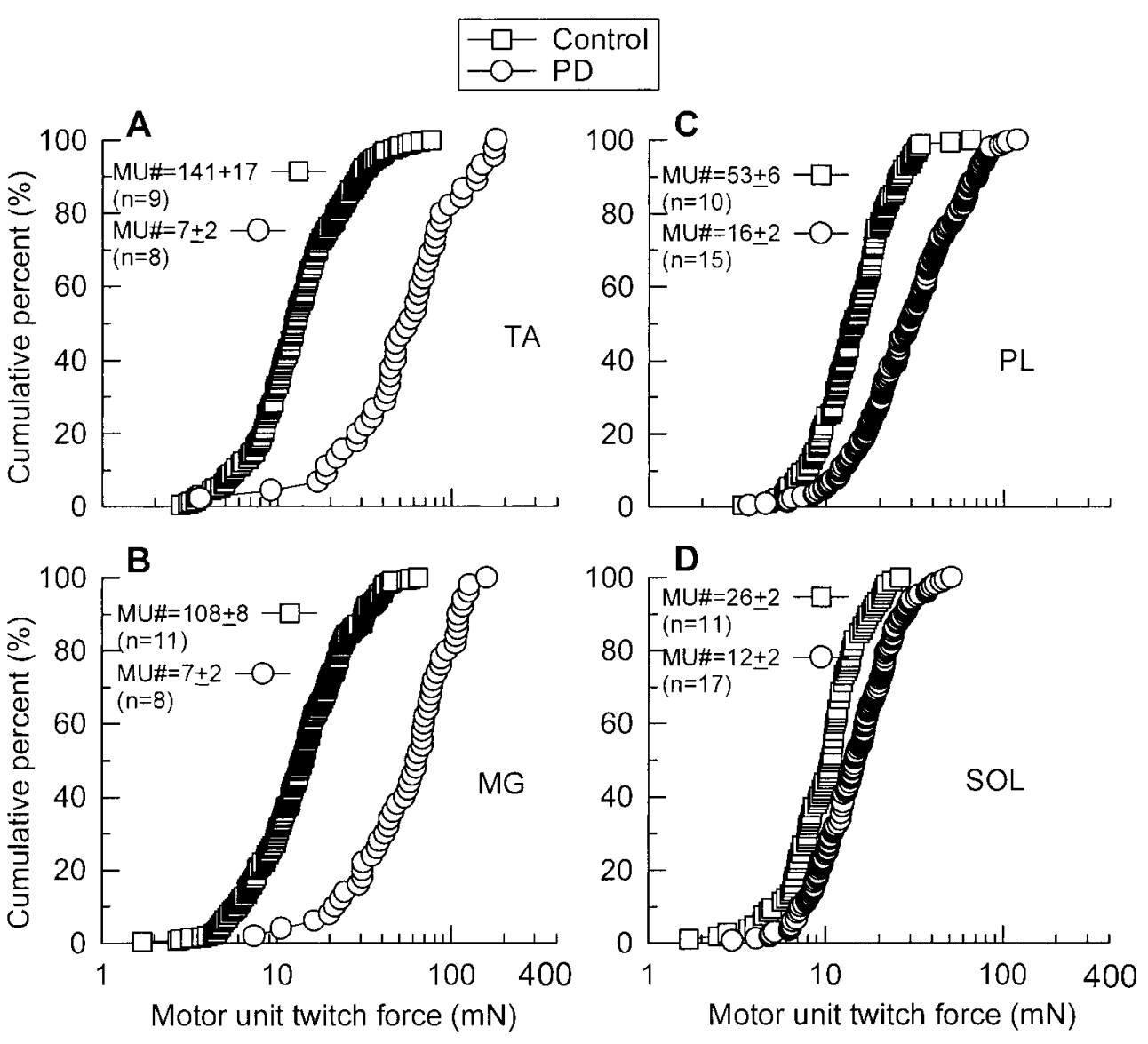

MUs after partial denervation, as shown previously for populations of MUs sampled from single animals (Rafuse et al., 1992).

The $<20 \%$ motoneurons that innervated the extensively denervated muscles enlarged their MU size by sprouting to compensate for the motoneuron loss. MU twitch forces, after normalization for muscle fiber CSAs (Table 1), increased approximately four- to fivefold on average in these extensively denervated muscles that experienced normal caged activity (Fig. $5 A, B)$. The parallel right-hand shift in the cumulative frequency histograms after partial denervation indicates that all MUs in the population enlarged by the same factor as shown previously in cat partially denervated MG muscles (Rafuse et al., 1992).

Comparisons of MU twitch forces in normal and partially denervated muscles that experienced normal caged activity were made after correcting for changes in muscle fiber CSAs. This is because meaningful comparisons of MU size in terms of IRs could be made, given that specific force of muscle fiber is a small contributing factor (Tötösy de Zepetnek et al., 1992a; Fu and Gordon, 1995a,b).

\section{MU enlargement by sprouting in moderately denervated muscles}

PL and SOL muscles suffered less severe partial denervation. MU twitch forces in PL and SOL muscles, which experienced normal caged activity, increased approximately twofold after moderate partial denervation (Fig. $5 C, D$ ), and the rightward shift of distribution was much less than that for the partially denervated TA and MG muscles (Fig. 5A,B). Nevertheless, the MU twitch forces in the partially denervated PL and SOL muscles, after normalization for muscle fiber CSAs (Table 1), were statistically higher as compared with control. These results are consistent with previous studies of partially denervated muscles in which significant 
Figure 6. Cumulative frequency histograms of MU twitch force distributions after normalization for CSAs in partially denervated TA $(A, C)$ and $\mathrm{MG}(B, D)$ muscles of rats experiencing normal caged activity (Control, $\bigcirc)$ as compared with partially denervated muscles after running exercise (Exercise, $A, B, \bigcirc$ ) and partially denervated muscles with FES (FES, $C, D, \mathbf{\square})$. The dramatic effect of increased neuromuscular activity in reducing MU enlargement was seen as a shift in cumulative MU force distributions to the left of the extensively denervated TA and MG muscles in rats that experienced normal caged activity $(p<$ $0.05)$. For $T A, n^{\prime}=45$ (Caged), $n^{\prime}=34$ (Exercise), and $n^{\prime}=18$ (FES); for $M G, n^{\prime}=$ $50($ Caged $), n^{\prime}=54$ (Exercise), and $n^{\prime}=69$ (FES) $(n=$ total number of muscles sampled for the calculation of the mean MU numbers; $n^{\prime}=$ total number of MUs sampled for MU twitch force measurement).

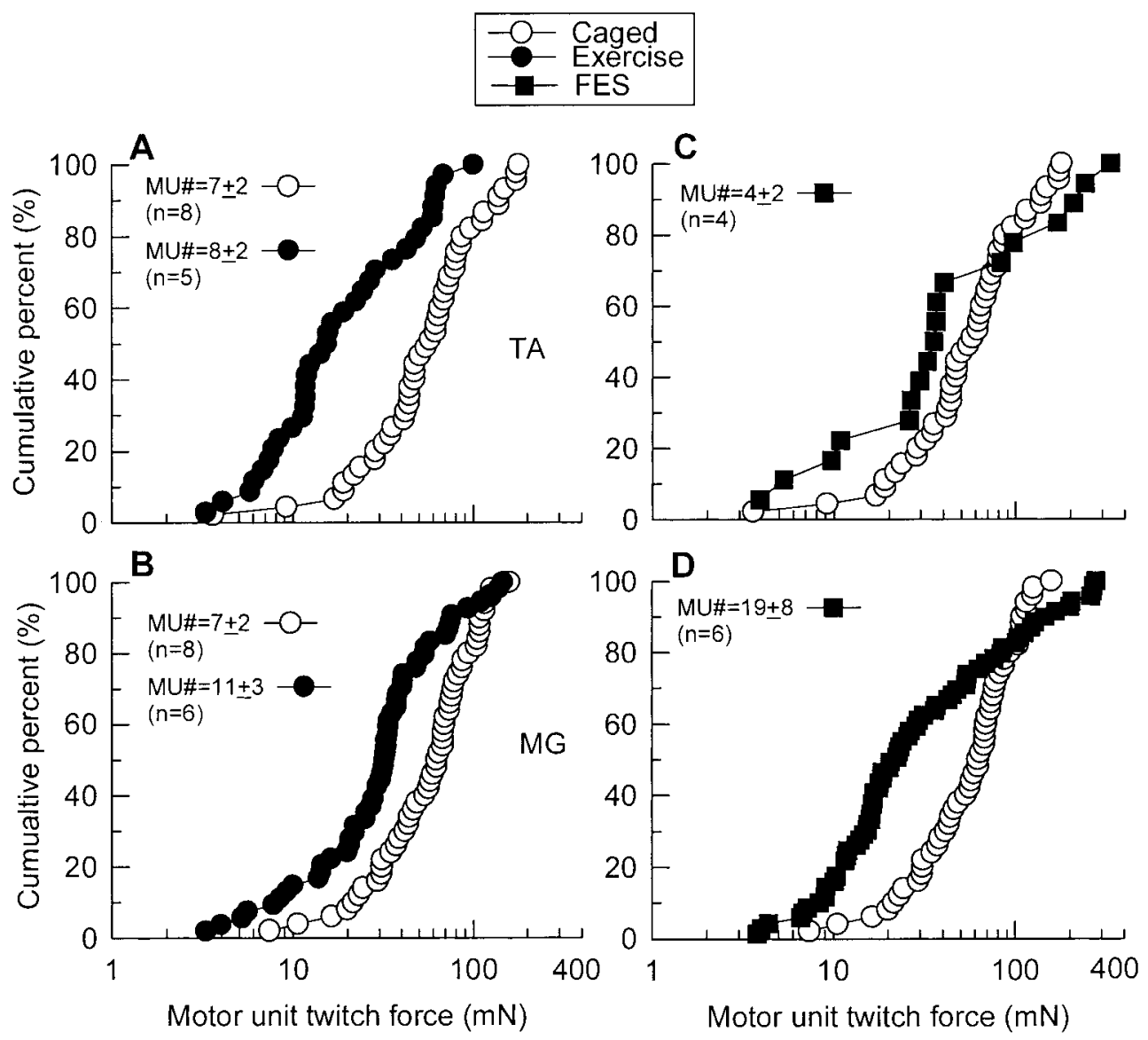

increases in MU size were not always detected until MU number was reduced below $50 \%$ of normal (Rafuse et al., 1992). Variability among animals in the extent of partial denervation may be a contributing factor.

\section{Neural activity reduces MU enlargement in extensively denervated muscles}

Effects of running exercise (average $1757 \pm 310 \mathrm{~m} / \mathrm{d}$ ) or FES (20 $\mathrm{Hz}, 8 \mathrm{hr}$ daily) on sprouting were examined in the extensively denervated TA and MG muscles. Increased neuromuscular activity severely reduced MU enlargement in the extensively denervated but not the moderately denervated muscles. Avulsion of L4 or L5 spinal roots resulted in significant reduction in the numbers of MUs in all experimental groups of partially denervated TA and MG muscles (Figs. 5A,B, 6). There were no significant differences in the number of MUs between the groups of caged activity, running exercise, and FES for both extensively denervated TA and MG muscles. The cumulative distribution histograms were shifted far to the left of the partially denervated TA and MG muscles in rats that experienced normal caged activity.

More detailed analysis of the cumulative frequency histograms, which compare MUs from high and normal levels of daily activity, showed that the detrimental effect of neuromuscular activity in reducing MU size was most pronounced for the smaller MUs and less so for the MUs that developed larger forces. Hence the sizes of the MUs in the extensively denervated TA and MG muscles, which developed forces of $<60-80 \mathrm{mN}$ under the normal control condition of "caged" activity, were either reduced considerably more than the larger MUs after exercise (Fig. 6A,B) or even enlarged after FES (Fig. 6C,D). The enlargement may indicate a small beneficial effect of activity on the largest MUs. One may argue that the larger MUs in partially denervated muscles might not be recruited during running exercise and therefore were spared from the detrimental effect of activity. This argument may seem likely, especially when one considers the study of Walmsley et al. (1978) in which treadmill locomotion required only 10-20\% of the maximal force output of the MU pool in the cat MG muscle and this relatively low force output was normally provided by slow and fatigued resistant units. In this study, however, denervation of TA and MG muscles was very extensive. Less than $20 \%$ of MUs remained in these muscles after extensive denervation. This remaining small number of MUs was likely recruited during running exercise. Most importantly, the sparing effect of the larger MUs was also evident in all partially denervated muscles with FES (Fig. 6C,D), which recruits all MUs. Given that low-threshold slow and fatigue-resistant units are involved in postural maintenance and locomotion (Burke, 1981), smaller MUs might very well be maximally active in the partially denervated muscles even during normal level activity (normal caged activity). Further involvement of these relatively small units in the increased level activity (running exercise or FES) might have overloaded the sprouting units and therefore resulted in reduction of MU enlargement. Furthermore, because the levels of running exercise for individual rats were similar, the possibility that different amounts of running exercise accounted for the differential effects on different MU types was discarded.

Our findings that activity might even promote MU enlargement in the larger MUs are consistent with the findings of Einsiedel and Luff (1994). In their study of the effect of 2 week 


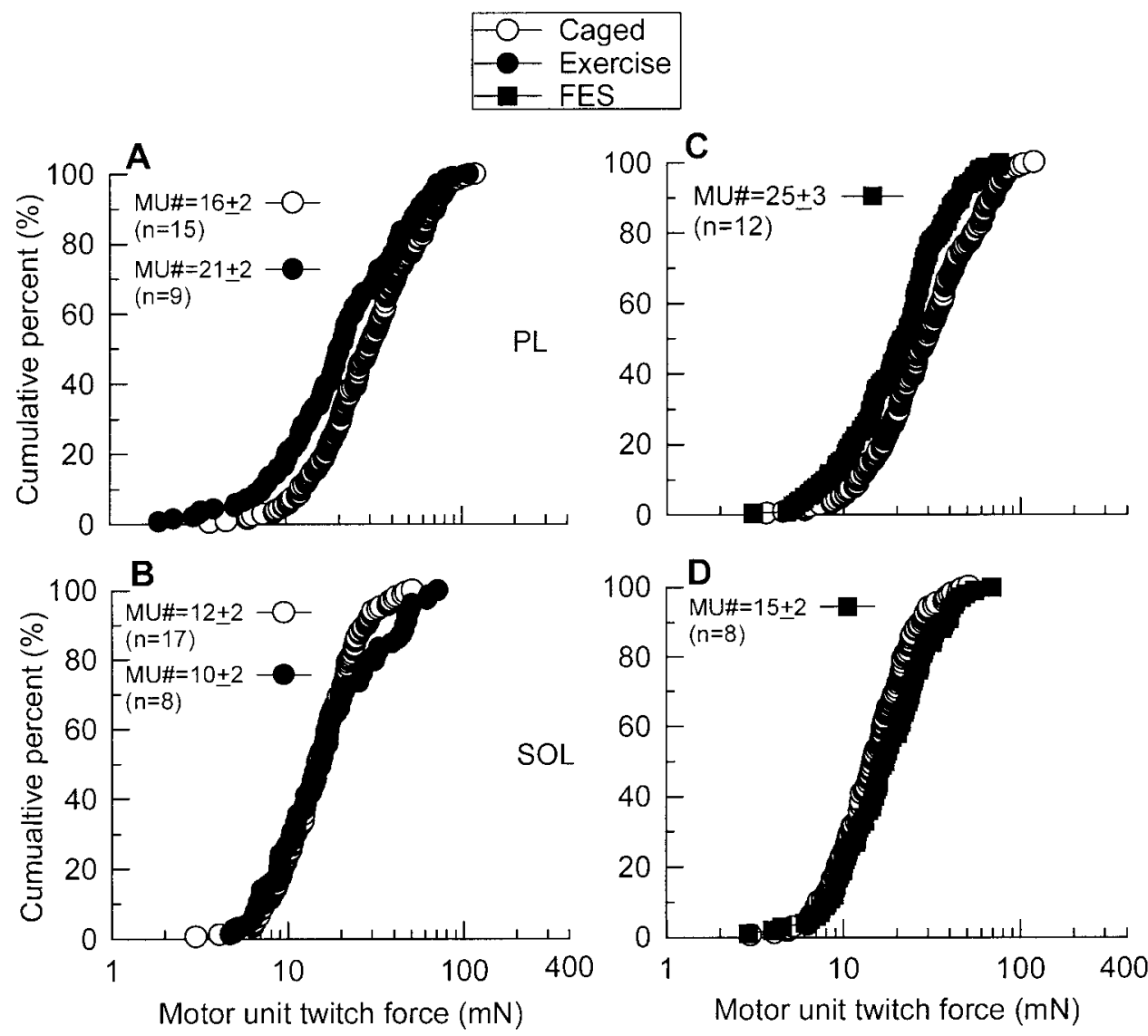

Figure 7. Cumulative frequency histograms of MU twitch force distributions in partially denervated $P L(A, C)$ and $S O L(B, D)$ muscles of rats experiencing normal caged activity (Control, $\bigcirc$ ) as compared with partially denervated muscles after running exercise (Exercise, $A, B, \bigcirc)$ and partially denervated muscles with FES (FES, $C, D, \mathbf{\square})$. There was a small but significant shift in cumulative MU force distributions, after exercise or FES, to the left of the moderately denervated PL muscle in rats that experienced normal caged activity $(p<0.01)$. For moderately denervated SOL muscle, there were no significant differences in the MU twitch force distribution between the caged and activity groups. For $P L, n^{\prime}=204$ (Caged), $n^{\prime}=139$ (Exercise), and $n^{\prime}=196($ FES $)$; for SOL, $n^{\prime}=169$ (Caged), $n^{\prime}=79$ (Exercise), and $n^{\prime}=100$ (FES) $(n=$ total number of muscles sampled for the calculation of the mean MU numbers; $n^{\prime}=$ total number of MUs sampled for MU twitch force measurement). treadmill walking on sprouting in partially denervated MG muscle suggested that there was a preferential effect of treadmill running exercise on promoting MU enlargement of fast-fatigable and fast-intermediate units on the basis of comparisons of mean MU forces in different MU types that were distinguished by fatigability test. However, because activity alters MU type to more fatigue-resistant MUs (Pette and Vrbova, 1992), analysis in terms of MU size, as in the present study, rather than type allows the differences in MU enlargement of different unit types to be detected more readily.

In summary, MU twitch force reasonably reflects IR after normalization for muscle fiber CSA (Table 1), as explained earlier. Therefore, the detrimental effect of increased neuromuscular activity on MU enlargement in extensively denervated TA and MG muscles could not be accounted for by the reduced muscle fiber size. The remaining effect therefore must be caused by a reduction in sprouting.

\section{Effect of neural activity on MU enlargement in moderately denervated muscles}

For the moderately denervated PL and SOL, increased neuromuscular activity by either running exercise (average $1757 \pm 310$ $\mathrm{m} / \mathrm{d}$ ) or FES $(20 \mathrm{~Hz}, 8 \mathrm{hr}$ daily) resulted in a small but significant decrease in MU size in PL muscle (Fig. $7 A, C$ ), but the effect was not detected in SOL muscle (Fig. $7 B, D$ ). The small shift of the largest MUs to even higher forces seen in the extensively denervated TA and MG muscles was also evident in these moderately denervated muscles (Fig. 7).

\section{Sprouting and effect of increased neuromuscular activity in moderately denervated muscles}

Using combined $\mathrm{Ag} / \mathrm{AChE}$ histochemical staining, three different types of collateral sprouts were examined in this study. A single axonal outgrowth, for example, originated from the node of Ranvier (Fig. 8A) (intranodal sprout) or preterminal region (Fig. $8 B$ ) (preterminal sprout). Another example is shown in Figure $8 C$. A single axonal outgrowth originated from the endplate area (Fig. 8C) (ultraterminal sprout). There was usually only one type of sprout per axon in moderately denervated muscle, with few exceptions, such as the examples in Figure $8 D$. An ultraterminal sprout originated from the endplate region of the same axon from whence an intranodal sprout originated. We also occasionally observed that many intranodal sprouts originated from a single axon (Fig. 8E).

In normal PL muscle, the typical pattern of innervation is shown in Figure 9, $A$ and $E$. The combined $\mathrm{Ag} / \mathrm{AChE}$ histochemical staining on $100-\mu \mathrm{m}$-thick cryostat longitudinal sections revealed, at high magnification (Fig. 9E), an intramuscular nerve trunk composed of several axons branching down into single axons that innervated single motor endplates.

As compared with normal PL muscle (Fig. 9A,E), we found that moderately denervated PL muscle $(<75 \%$ partial denervation) contained considerable numbers of collateral sprouts (Fig. $9 B, F)$. Nevertheless, there were some free endplates at 1 month. These collateral sprouts appeared to be mainly intranodal sprouts. The number and size of intramuscular nerve trunks were decreased, and the nerve branches became relatively longer con- 

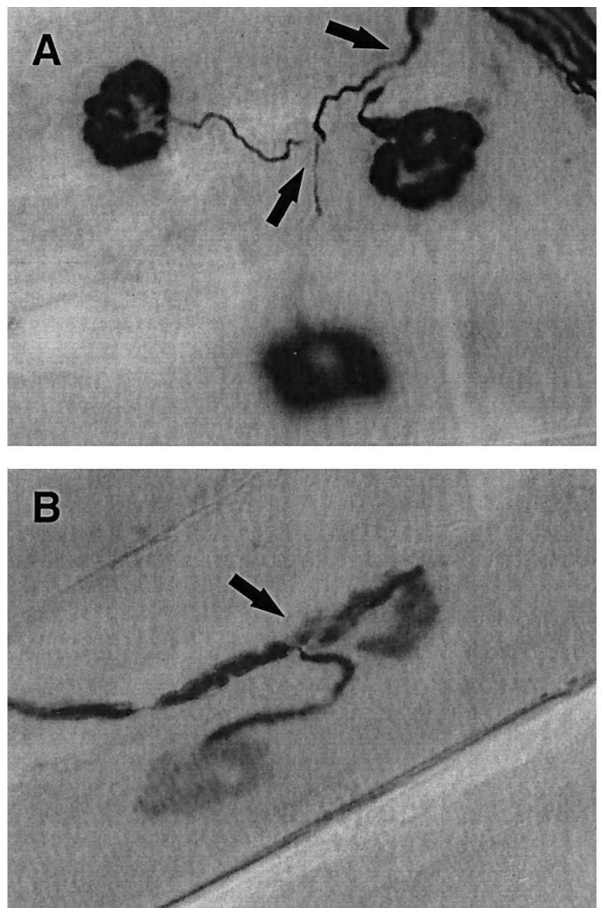
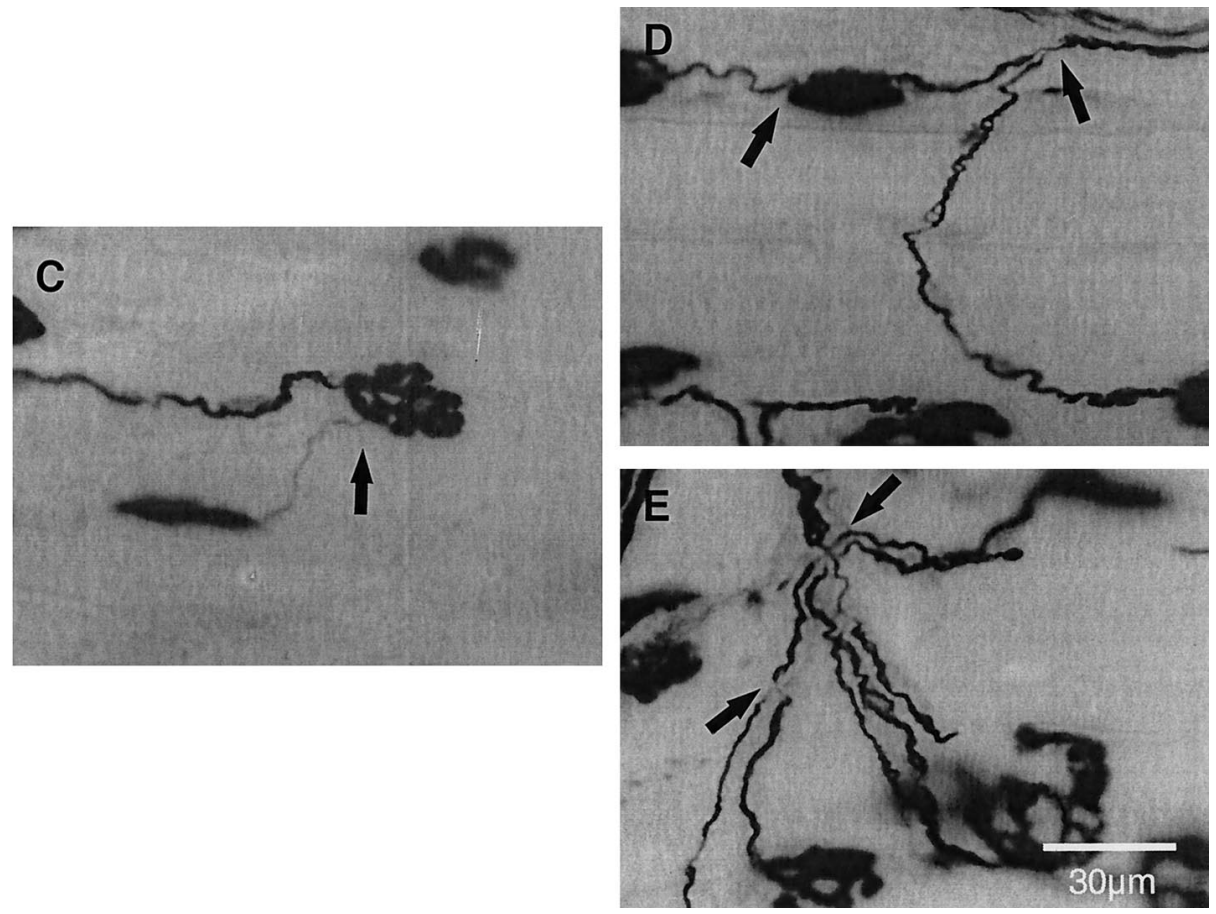

Figure 8. Photomicrographs of three different types of collateral sprouts: intranodal $(A)$, preterminal $(B)$, and ultraterminal $(C)$ sprouts, visualized with combined $\mathrm{Ag} / \mathrm{AChE}$ histochemical staining. In some cases, different collateral sprouts occurred in combination for the same axon $(D, E)$. Arrows indicate collateral sprouts.

sequent to the loss of axons and the extension of collateral sprouts to denervated endplates, respectively.

Increased neuromuscular activity by either running exercise (average $1757 \pm 310 \mathrm{~m} / \mathrm{d})$ or FES $(20 \mathrm{~Hz}, 8 \mathrm{hr}$ daily) did not appear to affect the extent of axonal branching or sprouting in moderately denervated PL muscles (Fig. 9C,D, $G, H$ ). We observed that the incidence of collateral sprouts and free endplates were comparable in both exercised muscles and muscles that experienced normal caged activity.

\section{Quantitation of the number of collateral sprouts in moderately denervated muscles}

Because (1) there were no significant differences in the relative proportion of different sprout types between PL and SOL muscles and (2) we obtained a similar range of the extent of partial denervation for both partially denervated PL and SOL muscles in each experimental group, we therefore grouped and discussed the results from PL and SOL muscles together in each experimental group.

The number of collateral sprouts and free endplates in normally innervated and partially denervated PL and SOL muscles and the effects of exercise and FES are shown in Figure 10. The few collateral sprouts $(\sim 3 \%)$ (Fig. $10 \mathrm{~A})$ present in normal muscles were also reported in the study of Eberstein and Pachter (1992). However, they were not the collateral sprouts involved in compensatory sprouting to reinnervate denervated endplates in partially denervated muscles. They were simply axonal branches involved in normal innervation in normal muscles; however, under the examining criteria used in this study, this normal branching could not be distinguished from the compensatory sprouting. The 10\% free endplates found in the normal muscles (Fig. 10B) were simply caused by the artifactual effects of muscle sectioning.

After moderate denervation ( $<75 \%$ partial denervation), the number of collateral sprouts increased significantly. Nevertheless, these failed to compensate for the loss of motoneurons as shown by the significantly higher number of free endplates. The small but significant reduction in $\mathrm{MU}$ forces after running exercise or FES (Fig. 7 $A, C$ ) was not detected as significant fewer sprouts or more free endplates in the small sample of PL and SOL muscles. Hence, the combined data of sprout counts of PL and SOL shown in Figure 10 were not statistically significant.

\section{Effect of increased neuromuscular activity on sprouting in extensively denervated muscles}

To obtain histochemical data to directly complement the electrophysiological evidence in extensive denervated muscles of the inhibitory effect of increased neuromuscular activity on sprouting, we extensively denervated TA muscles by avulsion of L4 spinal roots, subjected the rats to either normal caged activity or running exercise ( $8 \mathrm{hr}$ daily), and removed and prepared TA muscle for $\mathrm{Ag} / \mathrm{AChE}$ histochemical staining. In the extensively denervated TA muscle, sprouting was extensive (Fig. 11A-C). Despite the extensive sprouting, the proportion of free endplates (identified as endplates without axonal attachments) was very high (49\%) because of the limited capacity for sprouting and hence incomplete reinnervation of denervated endplates. Of the $51 \%$ innervated endplates, $\sim 41 \%$ of them were innervated by collateral sprouts. Extensively denervated TA muscle, after 4 week running exercise $(1569 \pm 278 \mathrm{~m} / \mathrm{d})$, appeared to contain very few collateral sprouts and a very high number of free endplates, as compared with those without exercise (Fig. 11D-F). The number of endplates innervated by sprouts was dramatically reduced from $\sim 41$ to $\sim 5 \%$ (Fig. $12 A$ ), and the number of free endplates increased correspondingly (Fig. 12B). Also shown in Figure 11, $D$ and $F$, were many vacant nerve sheaths caused by the extensive loss of motor axons and the inhibitory effects of exercise on sprouting. Figure $11 F$ clearly demonstrates that the endplates did not have axonal attachments and that the number of free 

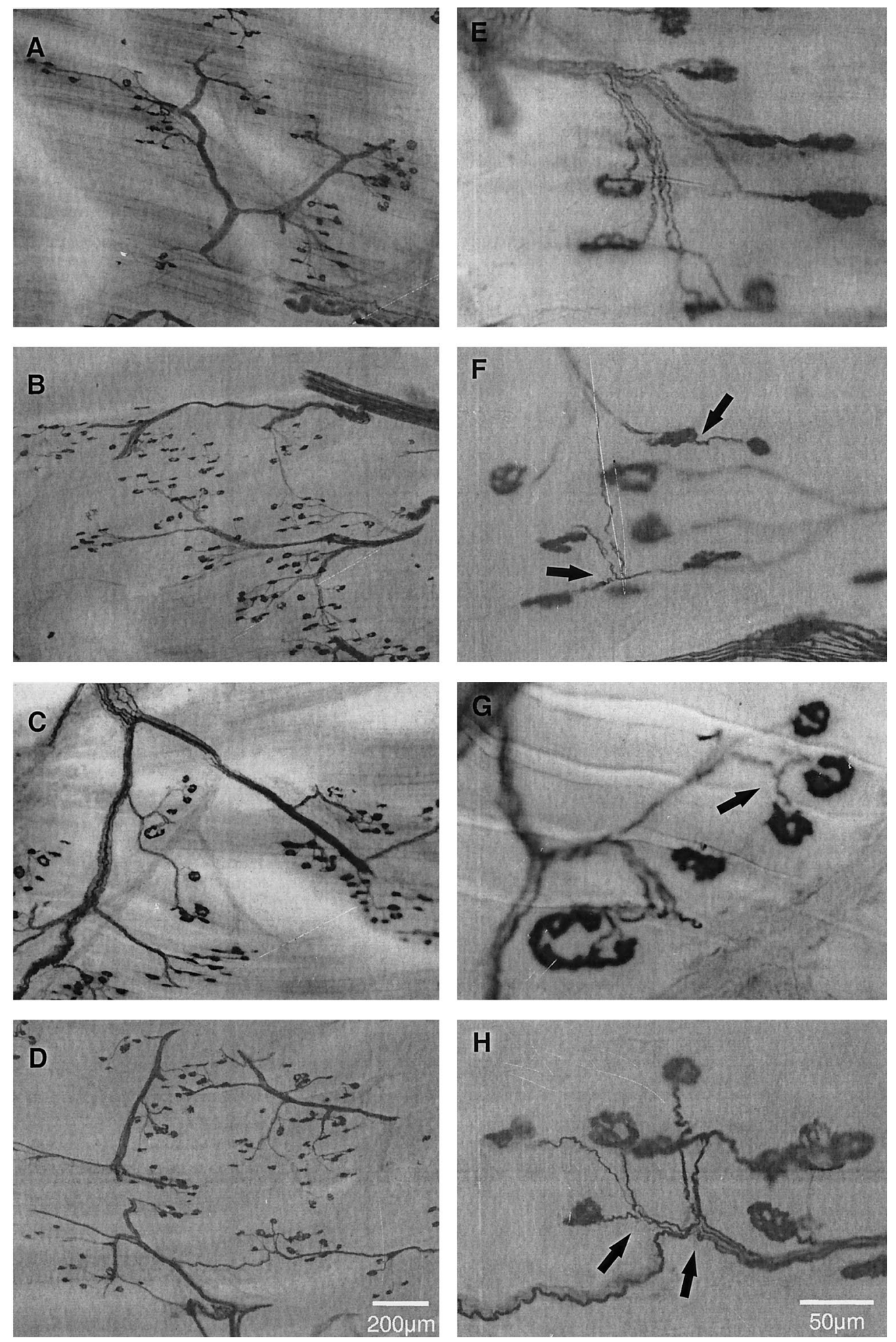

Figure 9. Low $(A-D)$ and higher $(E-H)$ power combined $\mathrm{Ag} / \mathrm{AChE}$ histochemical photomicrographs of $100-\mu \mathrm{m}$-thick cryostat longitudinal sections of control $(A, E)$, moderately denervated (PD $<75 \%$ ) after normal caged activity $(B, F)$, running exercise $(C, G)$, and FES $(D, H)$. In normal PL muscle, single endplates were innervated by single axons. For PD $<75 \%$, denervated endplates were reinnervated by collateral sprouts (arrows). There were no visual differences in branching and axonal sprouting after running exercise and FES. Shown are two intranodal sprouts and one ultraterminal sprout in $F$, two intranodal sprouts in $G$, and four intranodal sprouts in $H$. Arrows indicate collateral sprouts.

endplates was higher than in the muscles that experienced normal caged activity. Both the electrophysiological and histochemical results show that the effects of increased neuromuscular activity can be demonstrated at both the level of nerve innervation of endplates and the recording of MU forces.

\section{DISCUSSION}

The results of this study demonstrate that increased neuromuscular activity during the acute phase of sprouting compromises sprouting, particularly in extensively denervated muscles.
Detrimental effect of increased neuromuscular activity on MU enlargement and sprouting after extensive denervation but not moderate denervation

The striking finding of the present study that the detrimental effect of increased neuromuscular activity of reducing MU enlargement was evident largely in extensively denervated muscles may account for the contradictory findings in previous studies (Gardiner et al., 1984; Gardiner and Faltus, 1986; Michel and Gardiner, 1989; Seburn and Gardiner, 1996). The extent of par- 

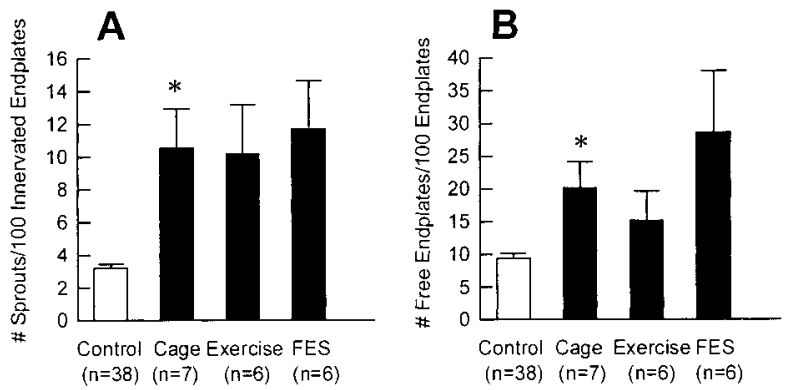

Figure 10. Mean $( \pm \mathrm{SE})$ of number of collateral sprouts per 100 innervated endplates $(A)$ and free endplates per 100 endplates $(B)$ of normal (open bars) and moderately denervated (filled bars) PL and SOL muscles after normal caged activity, running exercise, and FES. For PD $<75 \%$, the number of both collateral sprouts and free endplates was significantly increased as compared with control $\left({ }^{*} p<0.0001\right)(n=$ total number of muscles sampled).

tial denervation was not established directly in these studies, but on average the extent of partial denervation in the muscles studied, primarily the PL and SOL muscles, is $\sim 50 \%$. This moderate extent of partial denervation might be below the limits of detection of inhibitory effects of activity. The variability between animals in the extent of partial denervation makes it very difficult to detect any definitive effect of activity on mean MU size, particularly in the previous experiments in which the extent of partial denervation was not evaluated or quantitated. A twofold increase in MU size is difficult to detect electrophysiologically (Rafuse et al., 1992) and morphometrically (Brown et al., 1980), although a significant enlargement was noted for the whole MU population (Fig. 5). The effects of activity would be even more difficult to detect by average values that were used in most of those previous studies. Large samples of MUs are especially important when all MUs in partially denervated muscles are not affected similarly. As seen in Figures 6 and 7, it was evident in all four types of partially denervated muscles that increased neuromuscular activity was more detrimental to the smaller and slower MUs and that there was an apparent sparing of the larger MUs. It is important to take into account the effect of denervation/ reinnervation and neuromuscular activity on muscle fiber size, which was ignored in many of those previous studies. MU force is the product of the number, cross-sectional area, and specific force of muscle fibers innervated by a motoneuron, i.e., IR, CSA, and specific force. MU force depends on both IR and CSA and reasonably reflects IR and therefore sprouting, only if muscle fiber CSA is taken into account. Because specific force does not change after reinnervation (Tötösy de Zepetnek et al., 1992a; Fu and Gordon, 1995a,b), MU force corrected for muscle fiber CSA therefore provides a reasonable average measurement of MU enlargement.

\section{Proposed mechanisms for the detrimental effect of increased neuromuscular activity on sprouting}

The detrimental effects of increased neuromuscular activity in reducing MU enlargement in partially denervated muscles may be accounted for by the failure of (1) newly formed synaptic contacts to mature or (2) axonal sprouts to contact denervated endplates, or both. The former possibility is supported by evidence from studies of muscle reinnervation after nerve crush showed that synaptic maturation was retarded in rat muscles by increasing motor activity via a daily swimming regime of 3-4 hr/d for $35 \mathrm{~d}$ (Gutmann and Jakoubek, 1963) and in rat lateral gas- trocnemius muscles by $30 \mathrm{~d}$ treadmill running (Soucy et al., 1996). The hyperactive gastrocnemius muscles exhibited "tetanic fade" phenomenon, indicating that the activity had delayed the maturation of the synapses (Soucy et al., 1996).

The detrimental effects of increased neuromuscular activity in reducing MU enlargement in partially denervated muscles is more likely to be accounted for by the second possibility, namely that axonal sprouts fail to contact denervated endplates. A number of immunohistochemical studies have demonstrated that terminal Schwann cells at both innervated and denervated endplates induce and guide collateral sprouts by forming extended processes that bridge between the endplates (Reynolds and Woolf, 1992; Son and Thompson, 1995a,b; Son et al., 1996; Thompson and Kopp, 1996). The detrimental effects of increased neuromuscular activity in reducing axonal sprouting may arise indirectly from the inhibitory effects of increased activity on the ability of the terminal Schwann cell processes to make bridges between innervated and denervated endplates, and in turn, for the axonal sprouts to make contact with the denervated endplates. Striking evidence supporting this view comes from the recent studies of Love et al. (1997) and Tam and Gordon (1998). Love and colleagues (1997) reported that direct muscle stimulation prohibited bridge formation of terminal Schwann cell processes and thereby reduced axonal sprouting in SOL muscle $7 \mathrm{~d}$ after partial denervation. Studies of extensively denervated TA muscle also showed that the increased neuromuscular activity associated with running exercise did not affect formation of the Schwann cell processes; rather, it significantly reduced the bridging between endplates during the first week of collateral sprouting and, in turn, collateral sprouts at early time points over a 4 week period (Tam and Gordon, 1998). Interestingly, increased neuromuscular activity (Tam and Gordon, 1998) and direct muscle stimulation (Love et al., 1997) inhibited bridge formation and, in turn, axonal sprouting. In both cases, it was shown that the perisynaptic Schwann cells continued to make processes, but they failed to bridge between the denervated and innervated junctions.

Terminal or perisynaptic Schwann cells express muscarinic acetylcholine receptors that normally respond to ACh released from nerve terminals by influx of calcium (Jahromi et al., 1992; Reist and Smith, 1992; Reynolds and Woolf, 1993; Lev-Ram and Ellisman, 1995) and downregulation of glial fibrillary acidic protein (Georgiou et al., 1999). In the absence of released ACh at the denervated endplates, the perisynaptic Schwann cells would likely extend glial processes, which bridge between the innervated and denervated endplates in partially denervated muscles. It is possible that very high neuromuscular activity at the innervated endplates might release sufficient ACh to prevent the glial processes from effectively bridging between the denervated and innervated endplates and thereby explain the reduction in sprouting from the hyperactive nerve terminals.

In addition to the role of Schwann cells in providing physical guidance to sprout growth, Schwann cells may also produce sprout-inducing substances. Hoffman (1950) first suggested that collateral sprouts were guided to denervated endplates by some "elements" supplied by the denervated Schwann cells in the vacant nerve sheaths in partially denervated muscles. Since then, considerable evidence supporting this view has become available from subsequent studies on the role of non-neural cells of the distal nerve stumps and terminal Schwann cells in producing sprout-inducing factors to attract regenerating axons (David and Aguayo, 1985; Kuffler, 1987; Diaz and Pécot-Dechavassine, 1990; Kuffler, 1994). In light of the capacity of the neurotrophic factor, 

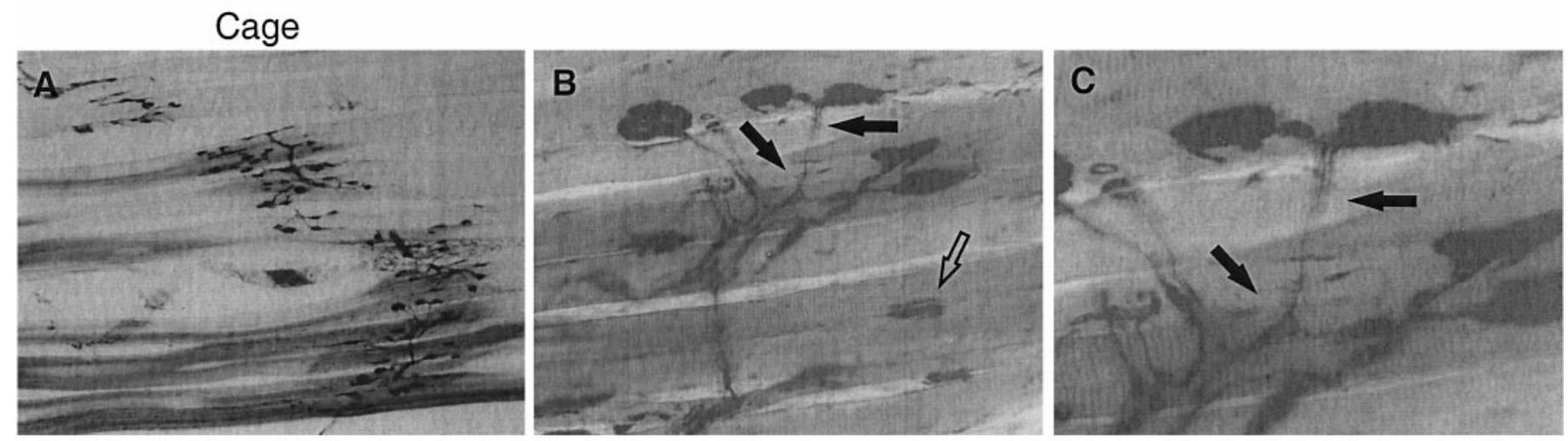

\section{Exercise}
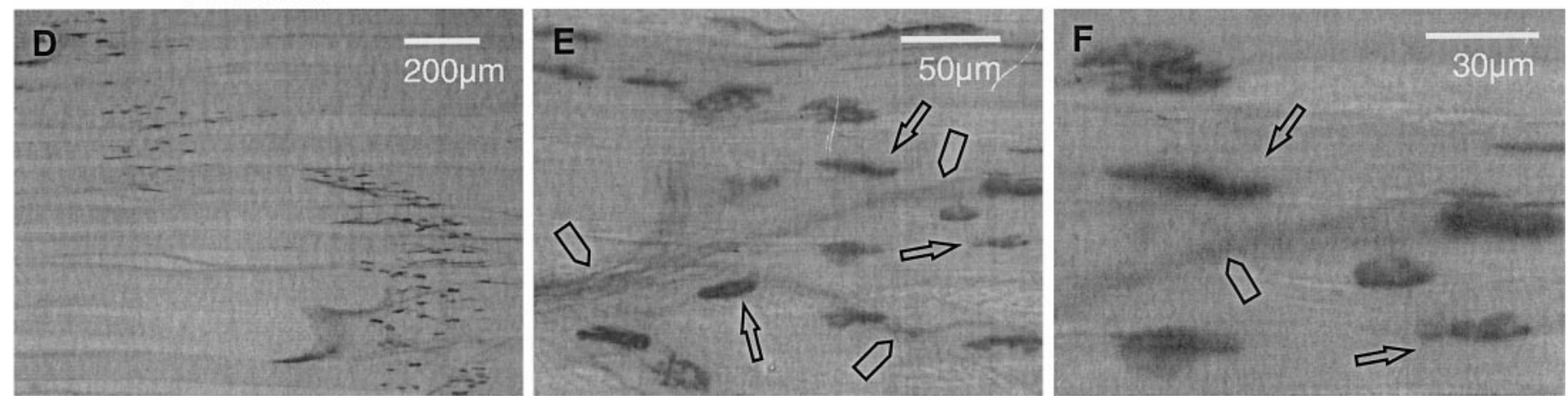

Figure 11. Three levels of magnification (low: $A, D$; high: $B, E$; higher: $C, F$ ) of combined $\mathrm{Ag} / \mathrm{AChE}$ histochemical photomicrographs of $100-\mu \mathrm{m}$-thick cryostat longitudinal sections of extensively denervated TA muscles with normal caged activity $(A-C)$ and after running exercise $(D-F)$. Extensively denervated TA muscles demonstrated extensive collateral sprouting for normal caged activity as designated by filled arrows in $A-C$. In contrast, the partially denervated muscles after running exercise contained almost no sign of collateral sprouts but contained very high numbers of free endplates, as identified by open arrows $(D-F)$. Rather, the exercised muscles contained many vacant nerve sheaths (arrowheads) containing no Ag-stained axons.

A

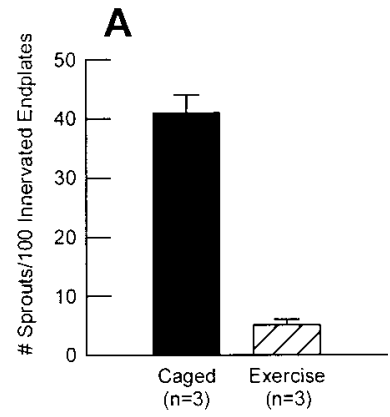

B

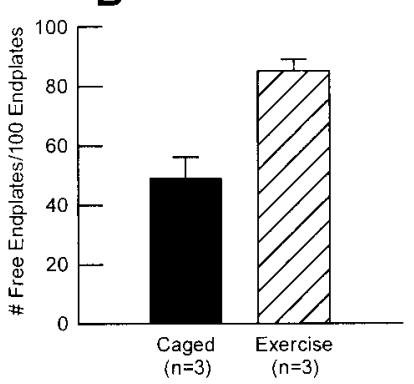

Figure 12. Mean $( \pm \mathrm{SE})$ of number of collateral sprouts per 100 innervated endplates $(A)$ and free endplates per endplates $(B)$ of extensively denervated TA muscle after normal caged activity ( filled bars) and running exercise (hatched bars) ( $n=$ total number of muscles sampled).

ciliary neurotrophic factor (Gurney et al., 1992; Kwon and Gurney, 1994; Siegel and English, 1997), to induce sprouting in normally innervated muscles, it is possible that expression of ciliary neurotrophic factor on partial denervation is altered and may thereby induce sprouting. Neuromuscular activity might somehow interfere with the ability of intact axons to respond to the sprouting stimuli.

Another source of sprouting stimuli is the denervated inactive muscle fibers (Brown et al., 1978a,b, 1980, 1981; Slack and Pockett, 1981; Pockett and Slack, 1982; Keynes et al., 1983; Gurney,

1984; Gurney et al., 1986; Kuffler, 1989; Rassendren et al., 1992; Kuffler and Luethi, 1993). Suggested sprouting factors released from inactive muscle fibers include insulin-like growth factors (Caroni and Grandes, 1990; Thompson and Kopp, 1996), neural cell adhesion molecules (Gurney et al., 1986), and neurocrescin (Nishimune et al., 1997). It has been shown that restoration of muscle activity by direct muscle stimulation inhibits axonal sprouting in paralyzed (Brown et al., 1977, 1980) and partially denervated (Brown and Ironton, 1977; Brown and Holland, 1979) muscles. The possibilities are that the direct muscle stimulation reduces the availability of sprout-producing factors from denervated muscle fibers and that, by stimulation of the intramuscular nerves, the stimulation might reduce the ability of the intramuscular nerves to sprout in response to the sprout-producing factors. Hence, the increased neuromuscular activity by the running exercise and FES in our present study could alter the ability of the Schwann cells at the innervated endplates to respond to the sprout-inducing factors from inactive muscle fibers and thereby reduce axonal sprouting.

Finally, levels of calcium in the nerve terminals may also play a role because the high intracellular calcium level induced by electrical stimulation and calcium ionophores results in cessation of nerve outgrowth (Kater and Mills, 1991; Rehder and Kater, 1992). Increased neuromuscular activity might overload sprout terminals with calcium, resulting in reduction of sprouting.

The aforementioned mechanisms are mostly postulated and yet 
to be proven. Nonetheless, one must consider these mechanisms in relationship to the differential detrimental effects of activity relative to the size of the MUs. Although we might predict that the mechanisms may be the same for all MUs, our findings demonstrate a selective effect of activity on the smallest as opposed to the largest MUs. In light of recent findings that the normal relationship between size of the motoneurons and the number of muscle fibers that they reinnervate was reestablished even under conditions in which all regenerating motoneurons and reinnervated MUs were subject to the same electrical activity (Gordon et al., 1999), it is apparent that the number of muscle fibers per motoneuron varies with motoneuron size rather than neuromuscular activity. Hence, the findings in this study that exercise or electrical activity reduced sprouting more in the smaller than the larger MUs reflect a balance between the intrinsic size-dependent capacity of motoneurons to enlarge their MUs by sprouting and the inhibitory effects of activity in limiting this sprouting.

\section{Conclusions}

Using four functionally different muscles and both electrophysiological and histochemical techniques, we, in the present studies, have resolved the controversial findings of previous studies on the effect of activity on sprouting and have been able to generalize the effect of increased neuromuscular activity in reducing MU enlargement and sprouting. The detrimental effect of increased neuromuscular activity in reducing MU enlargement and sprouting depends on the extent of partial denervation of muscles. Increased neuromuscular activity significantly reduced MU enlargement and sprouting primarily in extensively denervated muscles where only $<20 \%$ of intact MUs remained. We have demonstrated that normal physiological activity of sprouting motoneurons is conducive for MU enlargement during the acute phase of sprouting, whereas nonphysiological activity can be detrimental. The findings of the present studies indicate that increased neuromuscular activity is not recommended as rehabilitation immediately after motoneuron injury or in the early stages of motoneuron disease.

\section{REFERENCES}

Brown MC, Holland RL (1979) A central role for denervated tissues in causing nerve sprouting. Nature 282:724-726.

Brown MC, Ironton R (1977) Motor neurone sprouting induced by prolonged tetrodotoxin block of nerve action potential. Nature 265:459-461.

Brown MC, Ironton R (1978) Sprouting and regression of neuromuscular synapses in partially denervated mammalian muscles. J Physiol (Lond) 278:325-348.

Brown MC, Goodwin GM, Ironton R (1977) Prevention of motor nerve sprouting in botulinum toxin poisoned mouse soleus muscles by direct stimulation of the muscle. J Physiol (Lond) 267:42P-43P.

Brown MC, Holland RL, Ironton R (1978a) Degenerating nerve products affect innervated muscle fibres. Nature 275:652-654.

Brown MC, Holland RL, Ironton R (1978b) Is the stimulus for motoneurone terminal sprouting localized? J Physiol (Lond) 282:7-8P.

Brown MC, Holland RL, Ironton R (1980) Nodal and terminal sprouting from motor nerves in fast and slow muscles of the mouse. J Physiol (Lond) 306:493-510.

Brown MC, Holland RL, Hopkins WG (1981) Motor nerve sprouting. Annu Rev Neurosci 4:17-42.

Buller AJ, Pope R (1977) Plasticity in mammalian skeletal muscle. Philos Trans R Soc Lond B Biol Sci 278:295-305.

Burke RE (1981) Motor units: anatomy, physiology and functional organization. In: Handbook of physiology. The nervous system. Motor control, pp 345-421. Bethesda, MD: Am Physiol Soc.

Caroni P, Grandes P (1990) Nerve sprouting in innervated adult skeletal muscle induced by exposure to elevated levels of insulin-like growth factors. J Cell Biol 110:1307-1317.

Daniel WW (1995) Biostatistics: a foundation for analysis in the health sciences. New York: Wiley.
David S, Aguayo AJ (1985) Axonal regeneration after crush injury of rat central nervous system fibres innervating peripheral nerve grafts. J Neurocytol 14:1-12.

Diaz J, Pécot-Dechavassine M (1990) Nerve sprouting induced by a piece of peripheral nerve placed over a normally innervated frog muscle. J Physiol (Lond) 421:123-133.

Eberstein A, Pachter BR (1992) Recovery and loss of muscle force of rat plantaris after partial denervation. Exp Neurol 116:240-245.

Einsiedel LJ, Luff AR (1994) Activity and motor unit size in partially denervated rat medial gastrocnemius. J Appl Physiol 76:2663-2671.

Fu SY, Gordon T (1995a) Contributing factors to poor functional recovery after delayed nerve repair: prolonged axotomy. J Neurosci 15:3876-3885.

Fu SY, Gordon T (1995b) Contributing factors to poor functional recovery after delayed nerve repair: prolonged denervation. J Neurosci 15:3886-3895.

Gardiner PF, Faltus RE (1986) Contractile responses of rat plantaris muscles following partial denervation, and the influence of daily exercise. Pflügers Arch 406:51-56.

Gardiner PF, Michel RN, Iadeluca G (1984) Previous exercise training influences functional sprouting of rat hindlimb motoneurons in response to partial denervation. Neurosci Lett 45:123-127.

Georgiou J, Robitaille R, Charlton MP (1999) Muscarinic control of cytoskeleton in perisynaptic glia. J Neurosci 19:3836-3846.

Gordon T (1995) Fatigue in adapted systems: overuse and underuse paradigms. Adv Exp Med Biol 384:429-456.

Gordon T, Stein RB, Thomas CK (1986) Innervation and function of hind-limb muscles in the cat after cross-union of the tibial and peroneal nerves. J Physiol (Lond) 374:429-441.

Gordon T, Tyreman N, Rafuse VF, Munson JB (1999) Limited plasticity of adult motor units conserves recruitment order and rate coding. Prog Brain Res 123:191-202.

Gurney ME (1984) Suppression of sprouting at the neuromuscular junction by immune sera. Nature 307:546-548.

Gurney ME, Apatoff BR, Heinrich SP (1986) Suppression of terminal axonal sprouting at the neuromuscular junction by monoclonal antibodies against a muscle-derived antigen of 56,000 daltons. J Cell Biol 102:2264-2272.

Gurney ME, Yamamoto H, Kwon Y (1992) Induction of motor neuron sprouting in vivo by ciliary neurotrophic factor and basic fibroblast growth factor. J Neurosci 12:3241-3247.

Gutmann E, Jakoubek B (1963) Effect of increased motor activity on regeneration of the peripheral nerve in young rats. Physiologia Bohemoslovenica 12:463-468.

Halstead LS, Wiechers DO (1987) Research and clinical aspects of the late effects of poliomyelitis. White Plains, NY: March of Dimes Birth Defects Foundation.

Hoffman H (1950) Local reinnervation in partially denervated muscles: a histophysiological study. Aust J Exp Biol Med Sci 28:383-397.

Jahromi BS, Robitaille R, Charlton MP (1992) Transmitter release increases intracellular calcium in perisynaptic Schwann cells in situ. Neuron 8:1069-1077.

Kanda K, Hashizume K (1992) Factors causing difference in force output among motor units in the rat medial gastrocnemius muscle. J Physiol (Lond) 448:677-695.

Kater SB, Mills LR (1991) Regulation of growth cone behavior by calcium. J Neurosci 11:891-899.

Keynes RJ, Hopkins WG, Brown MC (1983) Sprouting of mammalian motor neurones at nodes of Ranvier: the role of the denervated motor endplate. Brain Res 264:209-213.

Kuffler DP (1987) Long-distance regulation of regenerating frog axons. J Exp Biol 132:151-160.

Kuffler DP (1989) Regeneration of muscle axons in the frog is directed by diffusible factors from denervated muscle and nerve tubes. J Comp Neurol 281:416-425.

Kuffler DP (1994) Promoting and directing axon outgrowth. Mol Neurobiol 9:233-243.

Kuffler DP, Luethi T (1993) Identification of molecules in a muscle extracellular matrix extract that promotes process outgrowth from cultured adult frog motoneurons. J Neurobiol 24:515-527.

Kwon Y, Gurney ME (1994) Systemic injections of ciliary neuromuscular factor induce sprouting by adult motor neurons. NeuroReport 5:789-792.

Lev-Ram V, Ellisman MH (1995) Axonal activation-induced calcium transients in myelinating Schwann cells, sources, and mechanism. J Neurosci 15:2628-2637.

Love FM, Son YJ, Thompson WJ (1997) Muscle activity inhibits terminal Schwann cells from inducing of guiding nerve sprouts after nerve injury in the rat soleus. Soc Neurosci Abstr 23:244.1.

Luff AR, Hatcher DD, Torkko K (1988) Enlarged motor units resulting from partial denervation of cat hindlimb muscles. J Neurophysiol 59:1377-1394.

Michel RN, Gardiner PF (1989) Influence of overload on recovery of rat plantaris from partial denervation. J Appl Physiol 66:732-740.

Nishimune H, Uyeda A, Nogawa M, Fujimoto H, Fujimori KE, Taguchi 
T (1997) Neurocrescin: a neurite-outgrowth factor secreted by muscle in an activity dependent manner. Soc Neurosci Abstr 23:244.2.

Pette D, Vrbova G (1992) Adaptation of mammalian skeletal muscle fibers to chronic electrical stimulation. Rev Physiol Biochem Pharmacol 120:115-202.

Pockett S, Slack JR (1982) Source of the stimulus for nerve terminal sprouting in partially denervated muscle. Neuroscience 7:3173-3176.

Rafuse VF, Gordon T (1996a) Self-reinnervated cat medial gastrocnemius muscles. I. Comparisons of the capacity of regenerating nerves to form enlarged motor units after extensive peripheral nerve injuries. J Neurophysiol 75:268-281.

Rafuse VF, Gordon T (1996b) Self-reinnervated cat medial gastrocnemius muscles. II. Analysis of the mechanisms and significance of fiber type grouping in reinnervated muscles. J Neurophysiol 75:282-297.

Rafuse VF, Gordon T, Orozco R (1992) Proportional enlargement of motor units after partial denervation of cat triceps surae muscles. J Neurophysiol 68:1261-1275.

Rassendren FA, Bloch-Gallego E, Tanaka H, Henderson CE (1992) Levels of mRNA coding for motoneuron growth-promoting factors are increased in denervated muscle. Proc Natl Acad Sci USA 89:7194-7198.

Rehder V, Kater SB (1992) Regulation of neuronal growth cone filopodia by intracellular calcium. J Neurosci 12:3175-3186.

Reist NE, Smith SJ (1992) Neurally evoked calcium transients in terminal Schwann cells at the neuromuscular junction. Proc Natl Acad Sci USA 89:7625-7629.

Reynolds ML, Woolf CJ (1992) Terminal Schwann cells elaborate extensive processes following denervation of the motor endplate. J Neurocytol 21:50-66.

Reynolds ML, Woolf CJ (1993) Reciprocal Schwann cell-axon interactions. Curr Opin Neurobiol 3:683-693.

Ribchester RR (1988) Activity-dependent and independent synaptic interactions during reinnervation of partially denervated rat muscle. J Physiol (Lond) 401:53-75.

Seburn KL, Gardiner PF (1996) Properties of sprouted rat motor units: effects of period of enlargement and activity level. Muscle Nerve 19:1100-1109.

Siegel SG, English AW (1997) CNTF is required for denervationinduced sprout formation at the neuromuscular junction. Soc Neurosci Abstr 23:248.14.

Slack JR, Pockett S (1981) Terminal sprouting of motoneurones is a local response to a local stimulus. Brain Res 217:368-374.

Son YJ, Thompson WJ (1995a) Nerve sprouting in muscle is induced and guided by processes extended by Schwann cells. Neuron 14:133-141.

Son YJ, Thompson WJ (1995b) Schwann cell processes guide regeneration of peripheral axons. Neuron 14:125-132.

Son YJ, Trachtenberg JT, Thompson WJ (1996) Schwann cells induce and guide sprouting and reinnervation of neuromuscular junctions. Trends Neurosci 19:280-285.

Soucy M, Seburn K, Gardiner P (1996) Is increased voluntary motor activity beneficial or detrimental during the period of motor nerve regeneration/reinnervation. Can J Appl Physiol 21:218-224.

Tam SL, Gordon T (1998) Detrimental effect of neuromuscular activity on the ability of terminal Schwann cells to induce sprouting in extensively denervated tibialis anterior muscle. Soc Neurosci Abstr 24:413.16.

Tam SL, van der Sloot P, Archibald V, Tyreman N, Gordon T (1995) Is neuromuscular activity beneficial to motor axon sprouting? Presented at 6th International Symposium on Neural Regeneration.

Tam SL, Archibald V, Stein RB, Tyreman N, Gordon T (1996) Effect of neuromuscular activity on sprouting depends on the extent of partial denervation. Soc Neurosci Abstr 22:298.4.

Tam SL, Tyreman N, Gordon T (1997) Detrimental effect of neuromuscular activity on motor axonal sprouting in a rat model of motoneuron disease. Neurosci Net 59:59.

Thompson WJ, Jansen JK (1977) The extent of sprouting of remaining motor units in partly denervated immature and adult rat soleus muscle. Neuroscience 2:523-535.

Thompson WJ, Kopp DM (1996) Schwann cells accompany nerve sprouts induced in muscle by insulin-like growth factors. Soc Neurosci Abstr 22:297.7.

Tötösy de Zepetnek JE, Zung HV, Erdebil S, Gordon T (1992a) Innervation ratio is an important determinant of force in normal and reinnervated rat tibialis anterior muscle. J Neurophysiol 67:1385-1403.

Tötösy de Zepetnek JE, Zung HV, Erdebil S, Gordon T (1992b) Motorunit categorization based on contractile and histochemical properties: a glycogen depletion analysis of normal and reinnervated rat tibialis anterior muscle. J Neurophysiol 67:1404-1415.

Walmsley B, Hodgson JA, Burke RE (1978) Forces produced by medial gastrocnemius and soleus muscles during locomotion in freely moving cats. J Neurophysiol 41:1203-1216.

Yang JF, Stein RB, Jhamandas J, Gordon T (1990) Motor unit numbers and contractile properties after spinal cord injury. Ann Neurol 28:496502 . 